\title{
Structural and Contentual Complexity in Water Governance
}

\author{
Rudy Vannevel * and Peter L. M. Goethals
}

\author{
Department of Animal Sciences and Aquatic Ecology, Faculty of Bioscience Engineering, Ghent University, \\ Coupure Links 653, B-9000 Gent, Belgium; Peter.Goethals@UGent.be \\ * Correspondence: Rudy.Vannevel@UGent.be
}

check for

updates

Citation: Vannevel, R.;

Goethals, P.L.M. Structural and Contentual Complexity in Water Governance. Sustainability 2021, 13, 9751. https://doi.org/10.3390/ su13179751

Academic Editor: Peter Driessen

Received: 7 July 2021

Accepted: 20 August 2021

Published: 30 August 2021

Publisher's Note: MDPI stays neutral with regard to jurisdictional claims in published maps and institutional affiliations.

Copyright: (c) 2021 by the authors. Licensee MDPI, Basel, Switzerland. This article is an open access article distributed under the terms and conditions of the Creative Commons Attribution (CC BY) license (https:/ / creativecommons.org/licenses/by/ $4.0 /)$.

\begin{abstract}
Social-ecological systems and governance are complex systems and crises that affect those systems are likely to be complex as well. Environmental topics are multi-faceted with respect to both structure and content. Structural complexity is about societal and institutional organization and management, whereas contentual complexity deals with environmental (or societal) analyses, knowledge, and problem-solving. Interactions between both are manifold, and it is essential they are included in decision-making. Describing these interactions results in a series of nineteen units, arranged in a matrix according to their prevailing mutual dependencies. These units show dominant processes and concepts, representative of environmental analysis. This approach, called ACCU (aggregation of concepts and complex adapted systems units), is provided with evidence through practices of, in particular, water governance.
\end{abstract}

Keywords: water governance; complex systems; Pentatope Model; structural complexity; contentual complexity; systems thinking

\section{Introduction}

Water governance is characterized by a wide diversity of policy areas, decentralized water policy-making, a sectoral fragmentation of water-related tasks across ministries and public agencies, a diversity of actors involved in water policy making, and policy makers facing conflicting objectives [1]. On the other hand, numerous water-related issues deal with water quality, water availability, and aquatic life as a result of population growth, economic activities, and climate change. Content and context are part of a webbed structure, making any analysis or decision difficult and incomplete. They are at the basis of the 'governance gaps' defined by OECD [1] (policy gap, information gap, capacity gap, accountability gap, administrative gap, funding gap, and objective gap), potentially contributing to uncertainty in decision-making. This makes water governance a complex system.

Social-ecological systems are complex systems. Changes to these systems cause implications that are critical to their social, economic, and natural capitals. Climate change, biodiversity loss, shrinking natural resources, and pandemics lead to questioning the prevailing paradigms and call for more adaptive and integrative approaches to respond to societal shifts. Facing the many, large-scale complex issues of our contemporary society, policy makers too easily call for 'a holistic approach' - a buzzword— to deal with complexity. But holism is a worldview in the first place, which may be missing embedded practices. Dealing with threats to social well-being, economic welfare, and healthy ecosystems requires theoretical and conceptual approaches, and practical tools to disentangle apparently intractable societal situations. There is a need for transdisciplinary approaches, and recognition of the value of complex social-ecological systems analysis, strategic adaptive management, and even resilience [2]. At the same time, there is an increasing conviction that current economic practices and technological developments alone do not hold the solution to these kinds of issues, and even lose value in favour of stakeholders' involvement [3-5]. This results in a common and gradual shift from an evidence-based scientific-technological towards a more tentative social-involvement form 
of decision-making, in the way Gupta and Pouw [6] advocate 'inclusive development'. Whatever distinction can be made-knowledge-driven versus communication-driven, or science versus governance- they all combine content and organisation. Related to complex systems, this is experienced as contentual and structural complexity of our society. This will now be applied to environmental issues and illustrated where possible with examples of water governance.

A vast number of publications on water governance and management deal with the outcome of the decision-making process, including policy principles, policy and management instruments, and plans and programs. There is also a wealth of information on related processes discussing the relevance of regulations, science-policy interactions, and policy cycle analyses. To this end, the widely applied DPSIR concept could be of practical use, although practices remain too often restricted to a pressure-status impact analysis, omitting the drivers and responses [7]. This contrasts with the societal developments, resulting in intensified competition for water resources that challenges governances to allocate water between uses and users, at the same time facing growing competition for natural resources as a result of population growth, economic developments, and climate change [8]. Knowledge and cognition systems analysis and other thematic topics are part of contentual complexity. In this paper, the notion 'contentual' is preferred when it deals with content in general, and 'thematic' when it relates to content with some form of classification or ordination (such as disciplines, environmental issues).

Societal structures are founded on institutional organization, with networks and hierarchies of interactions between institutes that secure governance in general and decisionmaking in particular. There is a common belief that formal rules and practices result in formal decision-making, irrespective of individual choices and preferences. In reality, decision-making seems rather a socio-biological battlefield, dominated by competing forces within and between hierarchies that range from the individual to the global organisation. Recognizing the role of humans and related power shifts is key to addressing global challenges. One focus of this paper is therefore on arguing for the inclusion of the human factor in water governance, in particular when dealing with environmental complexity. Institutional and societal organisation, human resources and competences, as well as related processes (e.g., administrative procedures and social learning) and their properties (e.g., human behaviour and communication), are part of structural complexity.

There is, however, a broad overlap between contentual and structural complexity. In particular, management forms are tightly connected to both. As physical bodies of governance, public authorities combine content (e.g., environmental policy), structure (e.g., institutional organisation), and their overlap (organizational and environmental management). Complex societal issues show both contentual and structural complexity, which can be cogently illustrated by the developments of the 19th C industrial revolution. Its storyline combines four major developments: technological innovations, socio-economic developments, the sanitary revolution, and a call for institutional reform [9]. Central to this were the rapidly changing urban societies with numerous emerging issues requiring a new kind of governance. The increase of societal complexity at that time is comparable with the global trends experienced today. Figure 1 applies to both cases as it depicts the same characteristics: (1) a shifting societal equilibrium; (2) severe environmental/systemic impacts, challenging the ecosystem's value; (3) an increasing thematic (contentual) complexity; and, resulting from this, (4) an increasing structural complexity. Complexity increase requires at first instance insight into the functioning of complex systems (systems analysis). There is a growing belief that complex issues must be addressed by coupled human-natural systems approaches, but existing approaches in the water domain-including integrated water resources management (IWRM) or socio-hydrology-apparently do not meet the requirements needed for policy-making (see: [10]). Almost two decades after the implementation of the Water Framework Directive (WFD) [11], there is still a plea for integration with 'external' policies-in particular by integrating environmental and social objectives, urban 
water in a wider context, and the climate change policy as a whole—-that affect aquatic ecosystems [12].

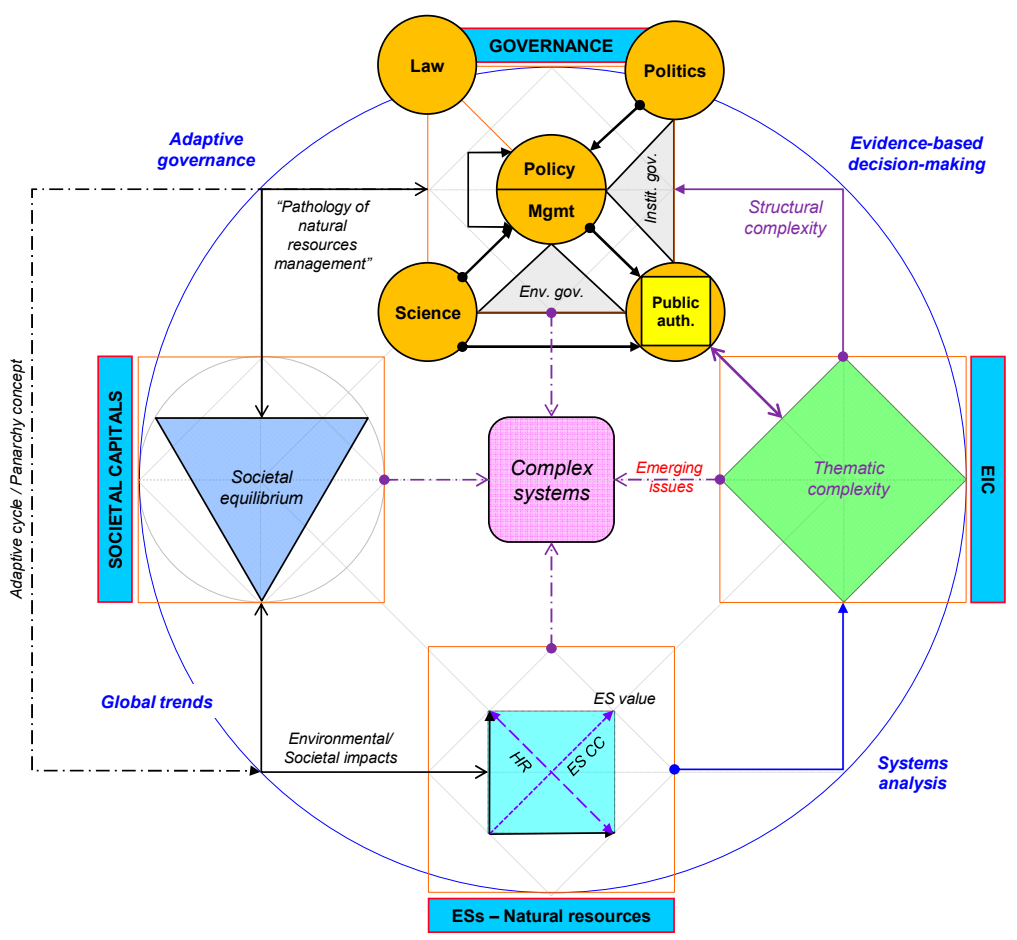

Figure 1. Governance adaptation and complex systems. Significant changes of societal conditions are the cause of and result from global trends and require adapted forms of governance. On the content side, thematic complexity increases, whereas on the management side this results in structural complexity. Public authorities should deal with institutional and environmental challenges to keep pace with increasing complexity. Abbreviations: authority (auth.), environmental information cycle (EIC), environmental governance (Env. gov.), ecosystem carrying capacity (ES CC), ecosystem (ES), habitat range (HR), institutional governance (Inst. gov.).

Dealing with complexity requires governance at different hierarchical levels. The subject matter of this paper is water governance. Water governance needs to be approached within a systemic framework, which requires the understanding of the key drivers of water resources management [13]. Akhmouch and Clavreul [14] (p. 2) define water governance as "encompassing political, institutional and administrative rules, practices, and processes through which decisions are taken and implemented, stakeholders can articulate their interests and have their concerns considered, and decision-makers are held accountable in the management of water resources and the delivery of water services"; the OECD as "the set of administrative systems, with a core focus on formal institutions (laws, official policies) and informal institutions (power relations and practices) as well as organisational structures and their efficiency" ([1] (p. 28); [15] (p. 2)). Recognising the overarching complexity of different systems involved, Corbett et al. argue, "that cross-systems integrations demands a more profound awareness of the deeper structures of organizational life (... ) than is generally recognized" [16] (p. 28). This paper aims to 'construct' a higher level of conceptualization by sorting out units and interactions that link contentual and structural complexity to governance. It should serve as a visualisation of the inherently vague holism concept, selecting a number of building blocks to be combined in different ways, detailed with an almost infinite number of properties and interactions. The proposed concept aims to meet the call for diagnostic tools to deal with the complexity of interactions that characterize multi-actor, multi-level, and polycentric governance regimes [17]. Its construction results from a number of previous studies by the authors, dealing with: 
I. The Pentatope Model (PT Model; [18]), a general approach for mapping environmental issues that includes interactions between societal capitals (CAPs), the environmental information cycle (EIC), and governance;

II. Increasing environmental complexity [19], that further elaborates on the EIC subframework of the PT Model;

III. The DPSIR-GASI concept [7]: an extension of the commonly applied DPSIR disturbance chain, focusing on the interactions between actors and subjects, the role of governance in the decision-making process (GASI: governance by actor-subject impact analysis), and water balances as a technical tool to support decision-making;

IV. Natural resources analysis [20], discussing the sustainable use of natural resources and related policy and management instruments by identifying key factors of ecosystem functioning.

This paper aims to explore and describe the conceptual basis of a 'holistic' approach to water governance. This is accomplished by developing a conceptual model of environmental analysis, combining elements of theories and practices of contentual and structural complexity into a single flow chart that allows us to navigate across complex adapted systems (CAS) units to analyse environmental issues. Showing an 'aggregation of concepts and CAS units' (ACCU) - which is a selection of CAS components and basic concepts of process functioning that relate to water governance, structured according to their most plausible interactions-should visualise the holism concept as a practical tool for problem analysis and communication, and to explore the limits of such a visualisation.

The main task of this paper is to explain the selection of the ACC-units and the way they 'communicate' with each other. The criteria for the selection are the applicability for environmental analysis as well as the 'cohesion' between units. To describe the units, a selection of terms, properties, and tools is used, preferably as found in literature. As advocated by Madani and Shafiee-Jood [10], inventing new terms and concepts is avoided if possible, although this does not always fit an integrated conceptual approach. The authors believe that it is up to the experts in the respective fields to review terms, definitions, and related classifications within a broader conceptual setting. Evidence and practices illustrate the importance and validity of each ACC-unit. A few applications indicate the beneficial use of the ACCU concept.

This paper further elaborates on Vannevel and Goethals's work [20], which explores the fundaments of ecosystem functioning and how this relates to sustainable use of natural resources. The focus is now on the way decision-making deals with it, considering risk management, organization structure, and governance forms. Here, too, the challenge is to combine a multitude of different aspects that relate to complexity in a dynamic and practical tool, aiming to foster insights and discussions. The idea to include 'risk' aspects logically emerged from the holism and systems thinking concepts, of which uncertainty is an inherent part. The content focuses on the interactions between the sub-frameworks of the Pentatope Model and GASI concept [7], in particular CAPs, governance, and EIC. The PT Model shows the sub-frameworks that are of importance when dealing with complex adaptive systems (CASs), including governance, CAPs, and EIC. Furthermore, the topic focuses on the environment (water domain). GASI is a common basis for the process behind DPSIR, and this paper illustrates the interactions between governance, societal capitals (actors), natural resources (subject), and the diversity of elements that relate to Environmental Impact Assessment (EIA; impacts).

\section{Major Components of Complex Systems}

The Pentatope Model [18] is used to illustrate and structure complexity at the supragovernance level. Figure 1 depicts the dynamism between four sub-frameworks of the Pentatope Model (societal capitals, ecosystems, the environmental information cycle (EIC), and governance). Complexity increase of environmental issues is a result of the number and intensity of significant disturbances (environmental changes), following the global trends that affect ecosystems. Global trends are of a very different nature and originate 
from a mixture of socio-economic and governance behaviour and decisions. They globally and locally shift the societal equilibrium and their impacts tend to outreach minimum requirements of ecosystem carrying capacity and habitat requirements. This interaction is discussed in Vannevel and Goethals [20]. Diversity and intensity of impacts are the main cause of complexity, requiring new knowledge, innovative tools, and adapted forms of (water) governance. However, adaptive governance itself contributes to complexity by its own dynamics, as is shown by Holling's Adaptive Cycle [21], applicable to both governance and ecosystem functioning. Even more meaningful in this context are the 'pathology of natural resources management' [21] and the Panarchy concept [22]. Dealing with complexity at sub-governance level necessitates the discussion of interactions between law, politics, science, and public administration, in order to support decision-making that serves policy and management.

There is no limit on the number, extent, and degree of complexity of complex systems. The figure shows governance and societal capitals as the principal components of complex systems when dealing with societal/environmental issues. Many of these issues are experienced as a shift of the societal equilibrium between the social, economic, and natural capitals. In the case of natural resources depletion, there is a mutual interaction between loss of ecosystem value and equilibrium shifts, deeply affecting the prevailing conditions of the capitals. Analysis of the natural system alone requires quite a number of thematic studies that should explain the size of the issues and the governance needs. In some cases, this thematic complexity forces structural adaptation (e.g., reorganization), which in its turn leads to an adapted form of governance. In this way, content and structure are intrinsically connected within a broader complex system that shows a number of functional properties.

\section{The Functioning of Complex Systems}

The understanding of systems behaviour is essential to governance when dealing with environmental issues, in particular the way the natural capital interacts with the social and economic capitals. Each capital is considered a complex adaptive system (CAS), defined by Pahl-Wostl [17] (p. 357) as "a complex, nonlinear, interactive system which has the ability to adapt to a changing environment". However, governance itself, as well as the actors involved, are part of complex systems. Systems complexity results from its inherent structure and functioning, and is characterized by (combinations of) $[2,7,10,17,21,23-33]$ :

1. multiple components (attributes, elements):

i. showing diversity (heterogeneity), such as actors and subjects, or, quantifiable (material flows, balances) and non-quantifiable (decision-making) content;

ii. structured according to a variety of scales and levels: multilevel (spatial, ranging from, e.g., habitats to biomes, and temporal, ranging from short to long term), hierarchical;

2. multiple interactions (relations) between components, including:

i. different forms: singular, multiple;

ii. different types: single, mutual (e.g., bottom-up vs. top-down);

3. interactions showing structural differentiation:

i. linear and non-linear (e.g., ramification, web-shaped), circular;

4. interactions showing behavioural differentiation:

i. $\quad$ static and dynamic;

ii. path dependency (depending on the previous step) vs. mutual dependency (e.g., domains of attraction according to Holling [34]);

iii. scale augmentation or reduction between related causes and effects;

iv. behavioural changes: adaptation, self-organization;

5. sequences of interactions resulting in a diversity of processes:

i. serial, parallel, and cyclic processes;

ii. destabilising forces, (non-)stationary and evolutionary processes; 
iii. lock-ins (i.e., no previous intervention), feedback loops (positive feedback, increasing returns, (self-)reinforcing, balancing, reciprocal);

6. processes having properties that result in systemic changes:

i. resilience, (in-)stability, oscillation;

ii. tipping-points, single or multiple or absence of equilibria;

iii. time delays, regime shifts, emergence, new system states;

7. systemic changes becoming unpredictable and unexpected:

i. $\quad$ spatial and temporal variability;

ii. indeterminate causality, increase of risks, increase of uncertainty, difficulties of probabilistic forecasting, limited predictability, irreducible uncertainties, unexpected responses;

8. a combined set of components, processes, and properties forming a system (structure, network):

i. hierarchy of subsystems versus nested networks;

ii. evolution from individual to complex systems;

iii. the potential of self-organisation in a non-equilibrium environment.

Examples of systemic behaviour show that complex systems are driven by fundamental characteristics of their constituents, in a way a social group functions according to its members' behaviour, or an ecosystem by its species traits. Environmental governance operates within a network of CASs. One example of such a network is a 'policy network', which is "a collection of stable relations among mutually dependent actors" [33] (p. 195). Studying governance modes of sustainable urban water management, van de Meene et al. [35] applies an approach of regime conceptualization comprising four elements: actors, processes, structures, and influences. Examples of combinations of characteristics include the Adaptive Cycle, the Panarchy concept, and the 'pathology of natural resources management' [21]. The 'pathology' illustrates a reinforcing feedback loop. It recalls similar concepts such as the rebound effect and Jevons paradox. Addressing environmental problems should involve dealing with these kinds of complexities and behaviour, and with the limits of policy and management control [32], to become aware that any environmental issue is part of a bigger systemic complex. However, being part of the policy-management nexus, decision-making results very often in linear processes that start with problem setting and end with implementing measures. Adaptive management, instead, commonly used in natural resources management, tends to include a feedback at every step of this process. [29].

It must be noticed that the CAS description deals with a structural description of systems, with the focus on the types of relationships between elements within complex systems, avoiding the proper identification of its components. Content that characterises societal functioning must be added to make systems thinking practical. The next paragraphs describe this content - an arrangement of selected CAS units and concepts-from a 'holistic' perspective, as far as it concerns environmental (and in particular water) governance and deals with contentual and structural complexity.

\section{Concepts and Practices}

To define the content and context of this paper (within the self-imposed restraints), a few publications could serve as an example. With respect to climate change adaptation, Maani [29] lists five key ingredients for adaptation planning:

1. Understanding and assessing vulnerability,

2. Managing risks,

3. Scenario thinking (to address specific impacts),

4. Identifying synergies and overcoming conflict (to meet the sustainability goals),

5. Awareness, leadership, and partnerships. 
These requirements are expected to be part of a bigger model description serving all kinds of societal issues, of which (adaptation) planning is but a small part. In this respect, Pahl-Wostl [17] proposes a framework of four dimensions that deal with governance: institutions (as formal and informal behaviour rules), actor networks, multi-level interactions, and governance modes. The challenge is to combine these and other concepts, classifications, and experiences described in literature in a single approach, attempting to be solid without being rigid.

Figure 2 shows an aggregation of different elements that are of importance when discussing the wider environmental complexity. The idea is to identify a number of units and to aggregate and detail these units according to the level and extent of the investigated environmental issue. This makes clear why the ACCU approach stands for 'aggregation of concepts and CAS units'. 'Concepts' refers to generic approaches and methods (including cartwheels, lists, and classifications), and 'CAS units' to components of complex adaptive systems (such as: governance, resources, thematic issues). The ACCU figure (Figure 2) shows the arrangement of 19 components from the perspective of environmental disturbances that result in impacts on (eco)systems, in their turn posing a risk to human society. Both mutually interact with structural and contentual complexity (visualised by a circle across the units). The other units are arranged according to their affinity with these four central units:

I. systemic impacts (SystImp): systemic hazard (SystHaz), systems value (SystVal), environmental information cycle (EIC);

II. risks and responses (RiskResp): decision-making (DecMak), societal capitals (CAPs), natural resources (NatRes);

III. structural complexity (StructComp): public governance styles (PubGovStyl), governance institutions (GovInst), organisational management (OrgMgmt);

IV. contentual complexity (ContComp): knowledge domains (KnowDom), disciplinary knowledge (DiscKnow), problem-solving strategies (ProbSolvStrat).

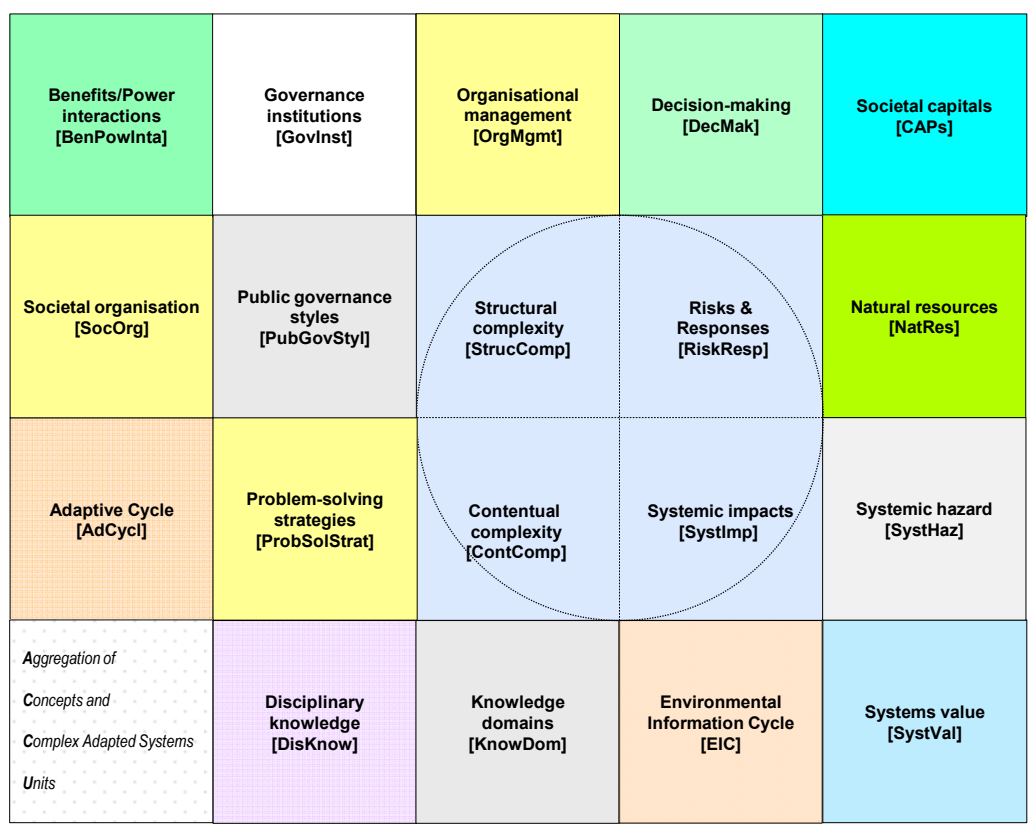

Figure 2. ACCU, showing an aggregation of units of complex adaptive systems, including elements of structural and contentual complexity and associated concepts. The arrangement applies to environmental disturbances (see text for further explanation).

Judgement on the affinity is based on examples in literature and personal experience, also revealing that 'second order' units have to be taken into consideration when analysing environmental issues: societal organisation (SocOrg), benefits/power interactions (Ben- 
PowInta), and the Adaptive Cycle (AdCycl). The Adaptive Cycle and benefit/power interactions are considered 'archetypes of systems dynamics', which is explained by Morgan [31] (p. 9) as "patterns of system behaviour that can be seen in many situations". They are basically intrinsic properties of systems functioning. On the other hand, law and politics-two out of five pillars of governance in Figure 1-are not explicitly part of a single unit. The role of 'law' is partly included in other units (norms in (SocOrg) and instruments in (DecMak)); 'politics' directly connects to a manifold of units and is therefore difficult to present in a flat schema. Nevertheless, depending on the topic, the building blocks can be selected and clustered in many ways according to the objective of the study, for instance, impact assessment, risk analysis, DPSIR, institutional organisation, co-operation and participation, and data and information flows. There is no single or specific entry point as it depends on the nature of the issue, the design of the research, and the background of the researcher to start with a particular unit.

ACCU presents an arrangement of units in a complex system that is at the centre of the Pentatope Model and integrated in different ways (Figure 1): natural resources with ecosystems, decision-making with policy and management, societal organization with societal capitals, systemic hazard with societal capitals and ecosystems, disciplinary knowledge with science, organizational management and governance institutions with public authorities and institutional governance, structural complexity and public governance styles with institutional governance, and thematic complexity with EIC. However, as the figure reveals, systems are getting more complex, since a number of units are also of importance when dealing with systemic processes: benefits and power interactions, the Adaptive Cycle, problem-solving strategies, knowledge integration, and public governance styles.

It still remains to explain the criteria used to structure content. Since it is the intention to develop a common scheme of environmental analysis, the boundaries of the topic to be investigated are determined by the disturbance chain (DPSIR) and GASI (governance by actor-subject impact analysis) concepts. The content is focused on (water) governance challenged by contentual and structural complexity. As a result, the analytical work consists of selecting, defining, and detailing appropriate units that are arranged in the most coherent way. There is no standard of how ACCU elements should be ordered and visualised, although a number of examples exists. One of them is the Iceberg Model of Systems Thinking [29], a four-level framework based on events ("incidents and happenings that alert us to a problem"), patterns ("the history of events, or trends of data over time"), systemic structures ("the interaction amongst drivers and factors that cause the problem"), and mental models ("deeper 'human factors' (... ) that underlie and affect all human decisions and actions").

Though conceptually sound, this kind of model lacks the dynamism to structure and the flexibility to include or exclude content, required when studying environmental issues. Figures 2 and 3 show one visualisation of ACC-units, illustrating-according to the areas defined by Buchanan [36] — a design of 'activities and organized services' in which showing connections and consequences is the central theme, as well as the design of 'complex systems or environments' that includes systems engineering and functional analysis. As such, the ACC-units are arranged according to their mutual dependency (e.g., one unit detailing another) and coherence (e.g., grouping units with the same conceptual basis), aiming at the same time to provide a tool for dealing with systemic complexity. This can be illustrated with environmental disturbances. Unknown and unexpected disturbances, impacts, and effects are at the basis of contentual and structural complexity. The way societal issues in general and environmental issues in particular are dealt with depends on the (potential) impacts of disturbances and their (potential) risks to society. Increasing levels (both in number and intensity) of disturbances contribute to complexity in the sense of reaching limits of understanding the nature and processes of these disturbances and the way to handle them. This makes, for instance, climate change not only a matter of droughts and biodiversity loss, but also a social, economic, and governance issue. Hence, contentual and structural complexity are not restricted to separate thematic or organizational issues, since there is a broad area in which both are combined. In fact, there seems always to be an 
area of mutual interactions. Increasing complexity is expected to unbalance or challenge existing pathways of knowledge and governance by questioning paradigms and structures. This is a key driver of CAS analysis. The ACC-units are described in the next chapter.

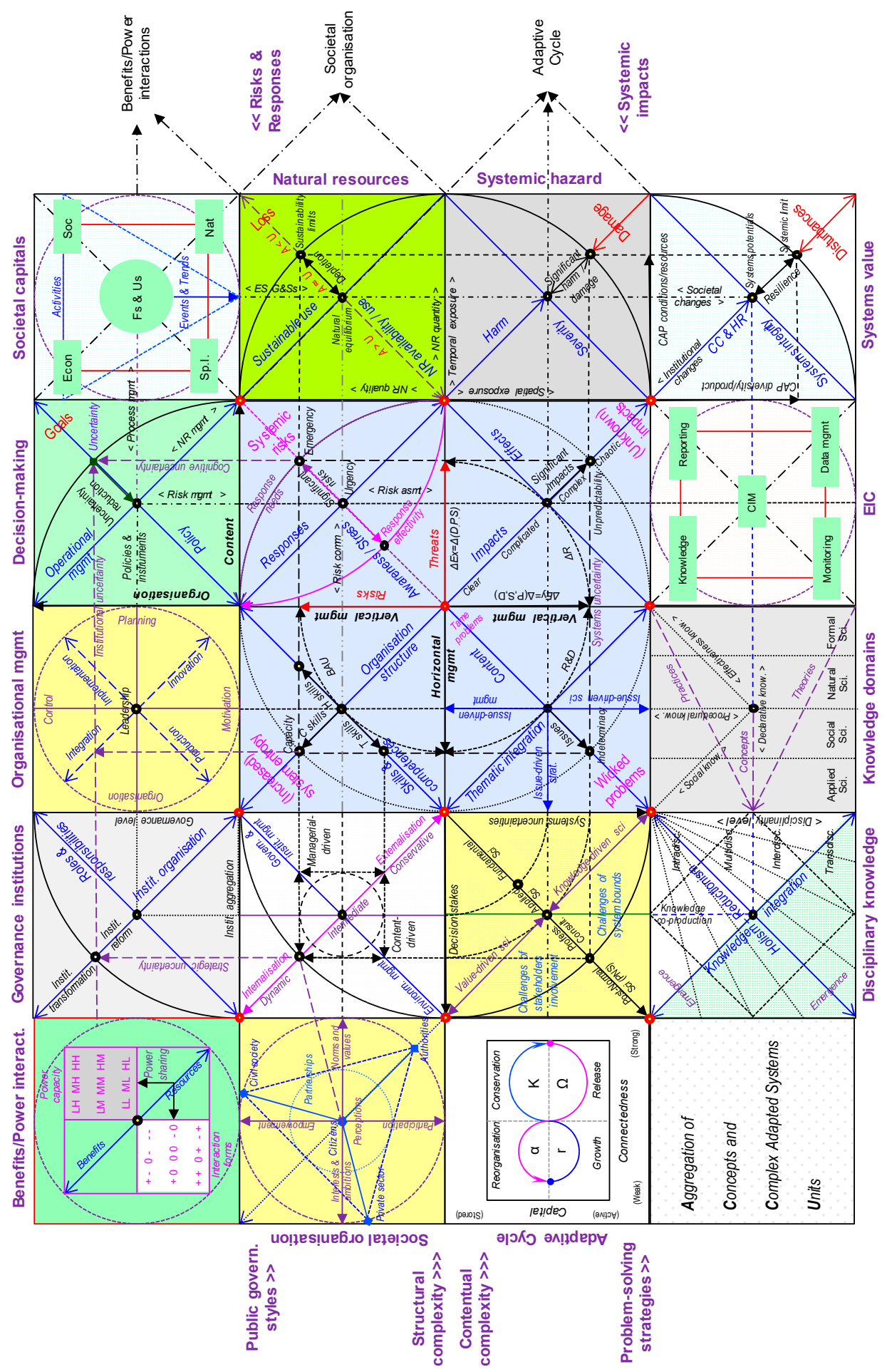

Figure 3. ACCU presentation, detailed. Main features of units are selected and presented in such a way that they show mutual dependencies and interactions. Abbreviations: assessment (asmt); availability (A); capital (CAP); business-as-usual (BAU); carrying capacity (CC); central and intermediate modules (CIM); communication (comm); conceptual, human, technical skills (C, H, T skills); disciplinarity (disc.); driving forces, drivers (D); economic, social and natural capital (Econ., Soc., Nat); ecosystem goods and services (ES G\&Ss); environmental (environm.); environmental 
information cycle (EIC); functions and uses (Fs\&Us); governance (govern.); habitat range (HR); highlow-medium (HLM); institutional (instit.); institutional aggregation (instit. aggreg.); management (mgmt.); knowledge (know); natural resources (NR); professional consultation (Profess. Consult.); research and development (R\&D); responses (R); status (S); science (sci.); spatial infrastructure (Sp.I.); strategies (strat.); use (U).

The ACC-units display different types of visualisations. Squares with diagonals show simple dependencies between two features, e.g., institutional organisation vs. roles and responsibilities in (GovInst). Circles within a square means that any element included can be pivoted, allowing the same kind of analysis but from the perspective of that element. For instance, authorities (in (SocOrg)) can be replaced by private sector or civil society; (BenPowInta) in relation with (SocOrg) can be analysed with respect to empowerment, interests, and ambitions, etc. Units illustrate relationships between characteristics of the elements, although this is not intended to be a graphical data presentation. Squares with diagonals and arches show ranges of conditions along the axes, projected on mutually dependent diagonals. The bullets on the intersections of diagonals and arches indicate the critical points of the unit content, the inner area being in general the 'known and controllable' part, the outer area the 'unknown and uncontrollable' part. Colours have no particular meaning and are intended to increase visualisation by marking different areas within a unit.

\section{Description of the ACC-Units}

See Figures 2 and 3 for the descriptions. Acronyms of ACC-units are shown as camel cases between (round brackets).

\subsection{Societal Capitals (CAPS)}

Concept. This 'capitals approach' is described by the Pentatope Model [7,18] and contains five factors: the economic, social, and natural capital, spatial infrastructure, and the process factor 'functions and uses'. The latter meets the opinion that processes between the capitals keep interactions stable and sustainable, as long as uses by one of the capitals do not distort this societal equilibrium. Distortion occurs when exceeding the limits of ecosystem goods and services (ES G\&Ss). In that case, human activities will be at the basis of events or trends significantly impacting ecosystems when crossing the limits of ecosystem resilience.

Description. Societal capital stands for the broader conception of human society, including nature as a valuable component of societal functioning. Terminology can be different (e.g., capitals, domains, or spheres) as well as the typology, showing a wide range of capital 'types' with similar or different meaning and/or content: social, economic, human, financial, natural, environmental, manufactured, and political. The selected 'capitals approach' is derived from the Pentatope Model [7,18] (Figure 1). The unit is part of a holistic framework designed for environmental analysis. It contains five factors: three main capitals (the economic, social, and natural capital), one additional capital (spatial infrastructure), and one additional process factor (functions and uses). Spatial infrastructure covers the nature/physical space and the constructed space, as indicated by Bastian et al. [37]. The basic idea is that interactions between the four capitals should maintain an equilibrium to keep a society sustainable, which means that distortion of properties and processes related to functions and uses of the capitals must be avoided. 'Functions and Uses' (Fs\&Us) is a common denominator of the role capitals play and the benefits they gain from each other. This is what production and consumption is in a socio-economic context. The role of Fs\&Us is widely applied to the discourse of sustainability and related ES G\&Ss, e.g., Bastian et al. [37] (p. 4) defines ecosystem functions as "the capacity of natural processes and components to provide goods and services which directly and/or indirectly satisfy human needs". Those needs seem to include also a less mechanistic, deeper functional role of society, that could be, as defended by Boik [38], the society's intrinsic purpose to achieve and maintain 
vitality within itself. In the case of the natural capital, uses refer to ES G\&Ss, with natural resources providing the goods and natural processes delivering the services. A societal equilibrium is not static but stands for a fluctuating status within boundaries, reflecting the dynamism of a resilient system. Interactions between capitals are mutual but not equal: the social and economic capitals largely depend on the natural capital; the spatial infrastructure is the physical exponent of any change in functions and uses, and stands at the same time for the availability and capacity of human and natural resources.

Functions and uses are at the heart of societal capitals: the social and economic capitals deploy activities, and the natural capital is a self-maintaining functional unit. The diversity, number, and intensity of activities impact CASs and may change the systems conditions and properties more or less fundamentally. Any activity or series of activities causing an effect of importance may be considered an event. If events last, they become a trend that eventually becomes widespread (global trend). When they have a significant impact on CASs in the sense that there is a cascade of events throughout the system, they could be considered societal impacts, changing the level or degree of impact, but not the relationships. Societal changes are societal impacts that fundamentally alter interactions between CAS elements. In the case of climate change, this change is a reinforcing cyclic process with global effects first (20th C.) that now tend to have large societal consequences.

Evidence. Capital approaches are widely used in environmental and governance analyses, for different reasons:

i. To emphasise the integration of humans in nature: Socio-Ecological System [23,24,39], Ecosystem Approach [40], SCENE model [41], CHANS-Coupled Human and Natural Systems [10];

ii. To assess the reaction of partnerships to environmental hazards [30];

iii. To address sustainable development: Four Spheres [42], Four Capitals Model [43];

iv. To address policy issues: 'sustainomics' [44].

\subsection{Natural Resources (NatRes)}

Concept. Natural resources (NatRes) represents the main aspect of natural capital. This unit can be replaced in a similar way by other human needs that are part of the societal capitals, for instance, 'economic products' or 'social life'. The unit shows how the natural equilibrium will shift when the use of natural resources exceeds sustainability levels that are defined by the availability of resources. Overuse results in depletion or even loss of resources.

Description. Natural resources (NatRes) is selected as a random societal capital element, representing a single property of the natural system, or in this case ES G\&Ss. Supply of ES G\&Ss depends on the functioning of ecosystems, which-in turn-is driven by ecological processes operating across a range of temporal and spatial scales [37]. This ACCU unit illustrates how natural capital is part of the societal capitals functioning, and influences or is influenced by systemic impacts and risks. Sustainable use, which is the selected objective (policy principle) that is formulated by the decision-making process, is dependent on the use of resources (both in terms of quality and quantity) according to their availability. The ratio 'availability $\mathrm{A} /$ use $\mathrm{U}$ ' equals the outcome of production versus consumption. NR use is sustainable when availability exceeds use $(A>U)$. The critical point of sustainable use is at the cross-point of 'significant harm to societal capitals' (SystHaz) and 'significant risks' (RiskResp). Exceeding this point means resource depletion $(A \approx U)$. In the case of ecosystems, this could be a reduced resilience or resources shortage. Use exceeding availability $(\mathrm{A}<\mathrm{U})$ means that sustainability limits are exceeded, which stands for loss of capital value (e.g., biodiversity loss) and environmental conditions that are harmful to society, indicating a state of emergency and unpredictability. Increase of loss means that the 'sustainability limits' point gradually shifts towards 'natural equilibrium'.

Natural resources, balanced against the sustainability criterion, is just one of the many capital elements to be considered when dealing with societal issues. It is interchangeable by or combinable with any other impact- or risk-related issue that requires risk management and decision-making, or with societal groups involved, and of which the nature is monetary 
(financial crises), human (brain-drain, pandemics), social (cultural diversity, poverty), or natural (climate change, biodiversity loss, habitat fragmentation). Natural resources are part of substance balances and material flows and hence relates to (SystHaz) and (SystVal). Resources are also visible as 'capital' in the (AdCycl); use of resources is part of (BenPowInta). Opposite to shrinking natural resources, this ACC-unit can also include a policy or management view, such as a habitat Leitbild or reference conditions (see: [45]).

Evidence. (1) With respect to the connection between (NatRes) and (SystHaz), the case of the groundwater-energy-food nexus in Iran shows that water use for crop production greatly overshoots the renewable water supply capacity of the country, making 'water bankruptcy' a serious national security threat in terms of economic and social impacts, which requires agricultural modernisation and policy reform [46]. In contrast, Eriyagama et al. [47] examines acceptable limits of water storage in Sri Lanka. (2) Ecological economists have become aware of the essential role of natural capital in commodity production, the biophysical limits to economic growth, the potential shift towards a steady-state economy, and the need of economic institutions and practices to drastically reform [48]. This means, for instance, as Baron et al. [49] (p. 1248) indicate for water resources management, the development of "a coherent policy that more equitably allocates water resources between natural ecosystem function and societal needs". In a similar way, Wuijts et al. [50] argue that assessing a river's needs, and identifying the needs that require improvement in order to achieve a good ecological status, are necessary to identify the governance needs to improve water quality. This directly refers to maintaining a sustainable natural equilibrium. The ecosystem conditions that limit ES G\&Ss are discussed by Vannevel and Goethals [20], and related time and space scales by Bastian et al. [37] and Ponnambalam and Mousavi [51]. (3) Species extinction is a real threat, and the maintenance of biodiversity is in fact part of our insurance policy [52].

\subsection{Systemic Impacts (SystImp)}

Concept. This unit deals with the widely applied DPSIR concept (see: $[53,54])$ to describe environmental disturbances and an impact scale. However, the DPSIR concept applies a slightly different meaning of the notion 'impact', that resulted in the 'extended DPSIR' [7]. An 'impact' stands for any actor-subject interaction (e.g., industry-river), of which the conditions of the latter may change ('effects'). Responses apply to any of the D, P, or $\mathrm{S}$ factors. Significant impact means a significant effect which may be unpredictable. The impact scale is based on the Cynefin concept [55]. The area of 'unknown impacts' coincides with (multiple) significant impacts of which the effects are unpredictable.

Description. In this unit, 'systemic impacts' combines a visualisation of the disturbance chain on the one hand, and an impact scale on the other hand. Environmental disturbances are conceptually underpinned by the DPSIR approach, the impact scale is based on the Cynefin concept.

In common terms, a disturbance is a sudden and profound change of a condition, following a (series of) events. The unit is constructed according to the 'extended DPSIR' which illustrates that 'an impact' stands for any interaction between driving forces (D), pressures $(\mathrm{P})$, statuses $(\mathrm{S})$, or responses $(\mathrm{R})$, causing a (significant) change in condition $(\mathrm{E}$, effect) over a period of time ( $\Delta$, which is between $T_{0}$ and $\left.T_{x}\right)$ (see: [7]). According to the D-P-S sequence, impacts between two of these factors (presented on the x-axis and y-axis) allow the following possibilities: $\Delta \mathrm{Ex}=\Delta \mathrm{D}>\Delta \mathrm{Ey}=\Delta \mathrm{P}, \Delta \mathrm{Ex}=\Delta \mathrm{P}>\Delta \mathrm{Ey}=\Delta \mathrm{S}, \Delta \mathrm{Ex}=\Delta \mathrm{S}>$ $\Delta \mathrm{Ey}=\Delta \mathrm{D}$. Combined, this is noted as $\Delta \mathrm{Ex}=\Delta(\mathrm{D}, \mathrm{P}, \mathrm{S})$ and $\Delta \mathrm{Ey}=\Delta(\mathrm{P}, \mathrm{S}, \mathrm{D})$. Responses $(\Delta \mathrm{R})$ apply to any effect $(\Delta \mathrm{D}, \Delta \mathrm{P}, \Delta \mathrm{S})$ or combination of effects. The figure shows impacts as interactions between $\mathrm{D}, \mathrm{P}$, and $\mathrm{S}$, and effects as changes of the conditions $\Delta \mathrm{Ex}$ and $\Delta \mathrm{Ey}$.

Impacts stand for any actor-subject interaction, regardless of whether this impact is significant [7]. Disturbances emerge from societal dynamics and have an increasing impact with increasing number and intensity of drivers and pressures (from actors, activities, and sources) and their effects on the status (subjects). Snowden's Cynefin concept [55,56], a 'sense-making model', distinguishes between four domains: clear, complicated, complex, 
and chaotic. As such, increasing impacts equal a higher level of complexity. When increase of drivers and pressures forces the status to its minimum or beyond (e.g., bad status in the case of severe pressures, such as pollution), impacts may initiate a cascade of higher order impacts within the (environmental) domain or other societal domains, and become unpredictable, both in nature and extent of the impact. The area beyond significant impacts is indicated as the area of unknown (or unexperienced) impacts, with conditions that become irreversibly altered, and impacts that are systemic. This means, for instance, decrease of the system's resilience (SystVal), systemic risks (RiskResp), loss of natural resources (NatRes), and unexpected damage (SystHaz). Unexpected refers to surprises-“a surprise occurs due to unexpected events" [57] (p. 15) - which are impacts that were or could not be foreseen or predicted. In this respect, the fact that maximising evidence means minimising surprise and hence uncertainty [57] relates the area of unknown impacts to (DecMak) and (ContComp) by reducing uncertainty and indeterminacy, respectively.

Unknown impacts are but one source of uncertainty, in terms of the intensification of existing as well as of the emergence of new impacts. Called 'cognitive uncertainty' that springs from a lack of technical knowledge about the nature of the issues, their impacts, and solutions [33], it also includes 'systems uncertainty' [25] that deals with systemic knowledge gaps. This area is experienced as contentually complex. Cognitive and systems uncertainty are indicated by Walker et al. [58] and Landuyt et al. [59] as, respectively, epistemic (e.g., model inaccuracy, imperfect knowledge) and stochastic or variability uncertainty (including natural variability, human behaviour, societal system dynamics, and technological developments). Landuyt et al. [59] offer a good example on this matter, combining the uncertainties of ecosystem services models and land use change models.

A significant effect also means an increasing level of severity (SystHaz) and environmental or societal stress (RiskResp). Severity is the social warning accompanying an environmental stress. When this stress reaches its point of urgency, severity is the warning signal that may reach a point of harm and calls for action in terms of human intervention and/or applying or developing knowledge. To this end, it is important to recognise that a significant impact stands for an issue.

Evidence. (1) Widely considered the main developments of global concern, global trends are well described by international authorities, including UN, OECD, and EEA [60-62]. The OECD [52] states that biodiversity loss has socio-economic consequences that translate into diminishing amenities, decreasing options for future generations, threatening current and future production, among others. (2) DPSIR is a widely accepted tool for environmental analysis, globally applied using an array of modified methods.

\subsection{Systemic Hazard (SystHaz)}

Concept. Hazard (harm, damage) to an (eco)system is caused when adverse impacts/effects change its conditions significantly. The point at which harm to the system will occur depends on the level of severity, determined by the impact intensity (including spatial and temporal exposure) on the one hand, and the vulnerability of the system on the other hand. Harm that exceeds the level of severity turns into damage. Damage affects the robustness of a system (resilience) until it becomes sensitive to degradation. Damage from unpredicted, unexpected, or unknown impacts may be irreversible and/or uncontrollable.

Description. A hazard (danger) is something (a source, a situation) that can cause harm or damage [63], which makes impacts potential sources of hazard. This unit elaborates on (SystImp) in the sense some effects result in (e.g., impacts from pressures) and others reduce (e.g., impacts from measures) harm or damage. It also relates to risk (RisResp) the probability a hazard will actually result into harm to a system [63] - that expresses the urgency of decision-making. Systemic hazards refer to the property of systems that impacts may cause damage to CASs. Hence, hazards must be explained in connection with (SystVal), considering the system's constitution ('integrity') is potentially affected.

This unit is developed upon the supposition that harm depends on the nature and intensity of the impact, temporal and spatial exposure, and on the systems' vulnerability. 
Worldwide and long-term impacts are likely to be more harmful to CAPs. A level of severity is reached when harm meets the system's vulnerability. Vulnerability is a collective term for the susceptibility of the (eco)system to disturbances, depending, inter alia, on its sensitivity/resistance, natural/impacted condition, complexity, integrity, (bio)diversity, and key elements (such as keystone species). Vulnerability is an intrinsic property of a system: low vulnerability means robust and resilient systems; high vulnerability refers to sensitive systems with a narrow resilience buffer. Levels of harm exceeding severity are significant and may result into damage. Damage can be broadly defined as "changes introduced into a system that adversely affect its current or future performance" [64] (p. 67). It is assumed that any CAS is resilient to some extent and that damage reduces resilience. Increase of damage will lower the systemic limit point as well as the system's resilience (SystVal) and reaches a critical level of severity when the system loses its potentials (SystVal). Hence, damage caused by significant disturbances, e.g., loss of a keystone species, may turn complex natural ESs into rather simple impacted ESs. Degraded systems are expected to be less vulnerable, and of less value. Not all impacts—even significant-are deleterious since they include also recovery measures.

This unit includes elements of 'risks' according to the terminology of the United Nations Office for Disaster Risk Reduction (UNDRR) (Risk $=$ Hazard $\times$ Exposure $\times$ Vulnerability [65]), showing the factors' hazard, exposure, and vulnerability [66]. Hereby, it is assumed that harm or damage is a matter of both the duration of exposure (temporal exposure) and-where applicable — of the area exposed (spatial exposure). Apart from this mathematic-technical approach, there is the sociological perspective that considers risk an inherent characteristic of decisions in the light of hazardous events [30].

Damage (in an environmental context) means "a measurable adverse change in a natural resource or measurable impairment of a natural resource service which may occur directly or indirectly" [67]. However, additionally, unexpected or irreversible damage is likely to occur when impacts are unknown; unknown impacts are expected when the number of impacts increases; the number of impacts increases with a higher number of pressures causing more and stronger effects. Global warming has all of these aspects. Significant impacts compare with significant harm or damage of which the conditions are or tend to be unexpected, unpredicted, irreversible, or uncontrolled. This range compares with resilience (SystVal), resource depletion (NatRes), significant impacts (SystImp), significant risks (RiskResp), and knowledge issues (ContComp).

Evidence. (1) According to Peterson [68] (p. 329), "the sensitivity of a system to changes in its sub-systems or its environment depends upon its internal state". This is a basic concept in environmental indicators. Biotic indices for freshwater assessments-as many other biological assessment methods-are based on the value and vulnerability of ecosystems, and damage they experience from disturbances. The vulnerability of a central Asian river basin to stressors was examined by de Boer et al. [69], and the flood hazard was modelled in the Indus river basin in Pakistan [70]. (2) Temporal and spatial effects are omnipresent in environmental analyses. van Klink et al. [71] evaluate temporal changes in total terrestrial and freshwater insect abundances and biomass, as well as the geographic distribution of such changes. (3) Lautenbach et al. [26] mentions off-site effects as a blind spot in ecosystem services research, being a substantial risk for the spatial spill-over rebound effect, in the sense that biodiversity protection policies in one area may have even stronger negative effects in distant areas. (4) Related environmental threats are discussed by the EU [72]. (5) Limited fluvial space influences the river's ecological status, the hydro-morphological risk reduction, and human activities, whereas sufficient space contributes to ecosystem resilience [45].

\subsection{Systems Value (SystVal)}

Concept. This unit applies to any CAS and illustrates that increase of (significant and/or irreversible) disturbances lower the system's value, decrease the system's resilience, and eventually alter the system's integrity. Minimal resilience is marked by the point 
of 'systems potentials', and minimum levels of carrying capacity and habitat range are reached. Below this point, irreversible systemic changes occur. This unit complements (NatRes) and (SystImp), but also extends the idea that key factors of ecosystem functioning apply to other systems (social and economic capitals, governance, and institutions) as well.

Description. 'Disturbances' is used in this unit as a collective term for the totality of (significant or not-significant, positive or negative, natural or human-induced) impacts/effects related to D, P, S, and R (SystImp) that affect the value, resilience, and/or integrity of a system. Systemic changes mean that the integrity of the system envisaged is irreversibly affected, which may also cause changes to other societal capitals or CASs. This unit is based on Vannevel and Goethals [20], describing key factors of ecosystem functioning as components of ES value: natural conditions and resources, biodiversity, biomass, carrying capacity (CC), and habitat range (HR). In nature, HR is the extent environmental conditions allow species to occur (within a habitat). This is denoted as $\Delta \mathrm{HR}=$ (Conditions, Biodiversity). The ecosystem's CC depends on it and is the ability of species to use resources (which are part of the conditions) to produce biomass: $\triangle C C=$ (Resources, Biomass). This concept can be extended and applied to the main societal—social, economic, natural-capitals, supported by the assumption that any CAS functions according to its prevailing conditions and that available resources-either natural, monetary, or human-can only be used by some kind of actor (company, ethnic group, species) to produce value by means of a product (goods, knowledge, culture, biomass). The degree of resources use depends on the functioning of the (CAPs) (Functions and Uses). Hence, the CC of a CAS indicates the potential of a system to produce value of an economic, social, or natural (ecosystem) good or service. Any capital aims to maximize its CC - although limited by the available resources and 'surrounding' conditions-reaching its systemic limits (of CC and HR). Disturbances will increase or lower these limit points as well as the system's resilience. Resilience is the capacity to withstand impact/effects, which means the system is in a state of 'systems integrity'. Parrish et al. [73] (p. 852) combines integrity and resilience in a single description: "An ecological system or species has integrity or is viable when its dominant ecological characteristics (e.g., elements of composition, structure, function, and ecological processes) occur within their natural ranges of variation and can withstand and recover from most perturbations imposed by natural environmental dynamics or human disruptions." According to Nardini and Conte [45], ecosystem integrity and ecosystem health are similar, and in the case of aquatic systems dependent on the combined water, biotic, and hydro-morphological quality. Basically, it can be said that integrity of a system is about structural completeness (all required components are present) and functioning processes (all components interact with each other in the way they should). In the figure, the level of integrity indicates the degree of stability of the system; the area above this level covers resilience. This presentation fits best with the definition by Gunderson [74] (p. 435): "Resilience in ecological systems is the amount of disturbance that a system can absorb without changing stability domains". Hence, system's integrity strongly connects with system's vulnerability (SystHaz). Resilience of ecosystems is subject to natural fluctuations and trends, which (can) alter the functionality and capacity of ecosystems to supply ES G\&Ss periodically or permanently [37]. These trends are continuous impacts or effects until the critical point of the systems' integrity is reached, indicated with 'systems potentials'. Systems potential is an extension of 'the concept of natural potentials' that "aims to display the service capacities of an area as a field of options available to society for use, and also to take into account such categories as risk, carrying capacity and resilience" [37] (p. 4). System potentials equals a minimal societal equilibrium, a balance between capitals that should reach a minimum level to maintain all societal capital processes sustainably. Loss of natural resources (NatRes), impacts (SystImp), and damage (SystHaz) may force the system to conditions below the system's potentials, systemic changes being hardly reversible or irreversible, and the result is a transition to an adapted system with a different equilibrium and vulnerability, albeit with less value. Adapted systems may initiate societal (e.g., climate adaptation) and institutional changes, either negative or positive. Future societal changes are essential to sustainable development; 
they include changes in demand and supply of ecosystem services, demographic changes, behavioural changes, economic development, and policy changes [26]. In the case of the resilient ecosystems, systemic limits compare with sustainability limits (NatRes) expressed as, for instance, environmental quality standards (EQSs).

Evidence. (1) Changing pathways of biogeochemical cycles, and in particular controlling processes such as nutrients or key species, may cause loss of ecological resilience [22]. Holling and Meffe [21] (p. 332) stress, with respect to natural variability, "the constructive role that variation plays in maintaining the integrity of ecosystem function in the face of unexpected events", but also warn that fixed policy and management rules lead to systems that gradually lose resilience. (2) Following the EU Water Blueprint [75], the EEA [76] (p. 26) addresses clearly "working with nature and using an ecosystem's natural functions to accept the return of water back into the landscapes". This fits within the objective that the "maintenance of the processes and properties that support freshwater ecosystem integrity should be included in debates over sustainable water resource allocation" [49] (p. 1247). It was exactly on the 'integrity' point that Poff et al. [77] (p. 769) notice that "current management approaches often fail to recognize the fundamental scientific principle that the integrity of flowing water systems depends largely on their natural dynamic character". (3) Complexity of societal systems is recognized, as well as the need for sustainable development, requiring societal transitions [78].

\subsection{Environmental Information Cycle (EIC)}

Concept. The proposed environmental information cycle is derived from Vannevel [7] and explains the process of data and information generation, treatment, and use by means of related activities, connecting the five frameworks factors: Monitoring, Data management, Reporting, Knowledge, and the Central and Intermediate Modules (CIM). CIM includes any tool that can be used for data and information handling (software programs, data-warehousing, water quality models), as well as analyses and assessments (e.g., Environmental Impact Analysis (EIA)). This concept fits with other approaches, including MDIAK [78] and DIK [79].

Description. Quite a number of environmental information cycles exist. The one shown is developed within the concept of the Pentatope Model and applied to impact analyses (see: [7]) (Figure 1). The proposed EIC contains five frameworks factors: Monitoring, Data management, Reporting, Knowledge, and the Central and Intermediate Modules (CIM). Monitoring is about data generation and reporting is about information generation. Reporting ranges from data supply to information support (and hence analyses and assessments). Knowledge is about both data and information demand and use. As such, this fits with the Data-Information-Knowledge model (see: [79]). CIM stands for any available tool that can be applied to drive the other EIC factors, including:

i. For knowledge: decision-support tools, training, communication with users, data and information questionnaires,

ii. For monitoring: sampling and analysis techniques, remote sensing, data loggers,

iii. For data management: web-based knowledge platforms (providing data, tools, guidance and information to users),

iv. For reporting: data submission tools, interactive tools (e.g., dashboards and map viewers), searchable databases,

v. Any other application (e.g., water quantity and quality models) that combines one or more factors.

Examples of CIM that support policy and management (DecMak) include Environmental Impact Assessment (EIA; [80]) and Strategic Environmental Assessment (SEA; [81]). EIA is commonly applied for risk and scenario analyses and has the potential to deal with multiple environmental issues. A similar legal European instrument is the SEA, aiming for sustainable development in the policy and management phase of plans and programmes. System dynamics (SD) models are much more integrated to consider coupled human-natural systems [51]. 
As such, the EIC exemplifies the 'systems approach of the first generation', as termed by Rittel and Webber [82] (p. 137-138), with distinct phases of understanding the problem, gathering and analysing information, working out solutions, etc., while being inadequate for dealing with wicked problems "of which an image of the problem and the solution emerges gradually among the participants".

Evidence. (1) Feio et al. [83] offer a worldwide overview of biological aquatic monitoring and assessment (EIC), combining river quality with environmental stressors (SystImp) and restoration measures (RiskResp). (2) A number of approaches similar to (EIC) exist, of which the MDIAK-Monitoring, Data, Information, Analysis, Knowledge-concept from the EEA [78] is well known. (3) This ACC-unit primarily relates to physical impact analysis and covers the three lowest hierarchical levels of the 4- (or 5-) levelled DIKW pyramid: data, information, knowledge, (insight), and wisdom (see DIKW: [84,85]. Knowledge and higher levels are dealt with in (KnowDom) and (DisKnow]. Tolk [86] replaces 'wisdom' by 'awareness', to which is referred in (RiskResp). (4) Ponnambalam and Mousavi [51] extensively document the use of Coupled Human-Natural System (CHNS) models related to water management, integrating IWRM and socio-hydrology. Discussing the challenges of complex modelling, Ponnambalam and Mousavi [51] link the combined socio-hydrological and water resources modelling (CHNS) to time and space dimensions (SystVal), different levels or organization (panarchy in $(\mathrm{AdCycl})$ ), upscaling and downscaling modelling issues (thematic integration in (ContComp)), and the inclusion of institutional and governance challenges ((GovInst, DecMak)), with the focus on integrating the natural-physical and social systems (KnowDom). (5) Zhou et al. [87] apply system dynamics and optimal planning models to predicting and allocating water resources.

\subsection{Risks and Responses (RiskResp)}

Concept. This unit connects impacts to decision-making, based on the idea that awareness is needed to initiate responses. Awareness largely depends on knowledge, indicating that threats may become a significant risk to societal functioning at the point of urgency (lower limit). Beyond the point of emergency (upper limit), risks become systemic and unpredictable since the impacts are unknown. Decision-making aims to formulate effective responses, lowering threats and risks far below the point of urgency.

Description. This unit largely covers risk governance that consists of three major elements: risk assessment (identification), risk management (dealing with consequences), and risk communication (involving actors) [30]. Risk management also deals with responses as part of daily decision-making ('business as usual). Daily decision-making means that no issues reach the level of urgency; responses are the output of decision-making to improving governance processes. In case of urgency, responses are more likely to be measures, well-prepared in advance, as a tool in risk management. In this context, the terms events, threats, risk, and hazard must be explained:

i. Event: an occurrence (either positive or negative) following an action.

ii. Threat (danger): the likeliness an event will or may happen; an impact having significant negative effects. A societal threat stands for potential (negative) effects of disturbances resulting in changing conditions that exceed normal ranges. Threats are a function of the degree of impacts and increase when impacts become more hazardous. A threat is the likelihood an event will occur when conditions are favourable and is at the basis of a risk.

iii. Risk: the possibility (quantification) a threat (negative event) will happen, eventually including the quantification of the effects. A risk includes potential loss of value, which may be any part of the societal capital. A risk is the opposite of an opportunity, the chance an event having a positive effect will happen. Risk, in economics, is the possibility an event will occur; in sociology, risk is a characteristic of decisions in the light of hazardous events [30]. The latter recalls the terminology of 'uncertainty'.

iv. Hazard (harm, damage): the negative effects of events that occurred. 
Increasing threats and risks should raise awareness, cause stress, and provoke responses (measures), although the mere identification or increase of a threat or risk will not necessarily initiate action. Awareness and stress are very similar: awareness is about being conscious of changing conditions and stress indicates the necessity to act. Awareness/stress is needed to respond in a timely manner to unwanted or changing environmental conditions when significant risks are detected, and the responses are to be formulated by authorities. Unknown risks are expected when impacts are unknown and threats cannot be identified. Risks are therefore a source of uncertainty, enhanced by the fact this involves social choices and decisions. Hence, systemic (or complex) risks are not predictable by a function of probability and effect only, and are characterized by three challenges: complexity (cause-effect relationships), uncertainty (data availability), and ambiguity (in decision-making) [30]. The most appropriate definition of risk in this context is: "The probability or threat of quantifiable damage, injury, liability, loss, or any other negative occurrence that is caused by external or internal vulnerabilities, and that may be avoided through preemptive action." $[30,88]$ (p. 14)). From this perspective, a threat is something that is likely to occur; a risk means loss of capital value (harm) when a threat is effectuated with no preceding responses, and (part of) the responses include pre-emptive actions. It is a human and societal reflex of self-protection to avoid unknown or high risks, the challenge being to avoid or reduce (unknown) risks by means of appropriate responses. It is the nature and intensity of the threats and risks that define the required responses.

Very often, events (e.g., disasters) indicate the time point at which the level of emergency is reached, a long time after awareness was raised and urgent action was neglected. Urgency is the point people (decision-makers, public) become conscious of significant systemic impacts that require immediate responses.

Responses are the counterweight of impacts (both pressures and effects) and are intended to minimise risks. The effectivity (and efficiency) of responses is determined by, inter alia, the available policy and management tools and the implementation strategy. Responses are most effective when addressing pressures (source-oriented approach) and less effective when addressing effects (end-of-pipe measures). A lack of or ineffective responses may result in higher risk levels that make it less feasible to implement responses. Significant risk is the level of alert (between urgency and emergency) at which it becomes difficult to reduce impacts by means of regular responses. An increase of threat/risk at this level results in a decrease of response feasibility, for this requires institutional organisation, additional knowledge, and/or financial and human resources. The combination of increasing risk and urgency and a lack of response feasibility moves to a state of emergency, the limit point at which it is no longer feasible to reduce uncertainty as impacts are unpredictable.

Evidence. (1) "Emergency-driven situations have an impact on stakeholder engagement as they shed light on the weakness of governments to properly address the risks, and are windows of opportunity for doing better through new innovative partnerships" [14] (p. 5). (2) Wuijts et al. [50] conclude that it is important to governance conditions to dispose of a shared perception of risks, the use of transparent and smart decision-making and the monitoring of outcome (water quality improvement) rather than progress of measures. Reducing or eliminating perverse incentives like particular types of subsidies will decrease pressures on biodiversity from specific economic sectors (agriculture, transport), while improving overall economic efficiency. (3) Traditional regulatory instruments to address market failures such as command and control measures and market-based incentives, when well designed, are very effective in correcting unsustainable use of biodiversity resources [52]. (4) A review of the literature on nature-based solutions (NBS) in urban areas shows the benefits of NBS for improving water quality and urban microclimate, increasing biodiversity, and obtaining social co-benefits, and advocates the need for a systemic change from conventional water infrastructure to NBS [89]. Hence, NBS are considered more effective responses that relate to (SystImp), (SystHaz), (SystVal), and (DiscKnow). 


\subsection{Decision-Making (DecMak)}

Concept. Decision-making is a process that depends on both content and organisation, which is very often policy development and operational management, respectively. The output of this process is 'policies and instruments', a set of tools to make ideas and related strategies operable. The nature of the content mostly deals with societal needs that require initiatives, or issues which must be responded to by imposing measures. Decision-making on societal issues should meet goals (for instance, sustainable development) by establishing a societal equilibrium and reducing uncertainty that results from increasing risks. Those risks are not only related to natural resources, but to any part of societal capitals, as well as to organizations and governance.

Description. Decision-making is a process in itself and is presented here in a rather restricted context as an interplay of making choices (policy) and undertaking actions (management) when issues emerge. The output of this process is established by means of principles (general rules, including policy principles such as sustainability, circular economy, the polluter pays principle), goals (something that must be obtained), or objectives (goals to be met within a certain time). Although discussed here in a policy and management context, this ACC-unit equally applies to individual and collective choices.

Decision-making results from policy and management, mutually interacting with content (contentual) and organisation (structural). Policies and instruments are the products of policy and management, intended to achieve goals. According to Walker et al. [58] (p. 6), "policies are the set of forces within the control of the policymakers that affect the structure and performance of the system of interest", and a goal is "a generalised policy objective". Content relates to systems knowledge. With respect to natural resources, different management forms apply: process management to steer the societal capitals, natural resources management (NR mgmt) to maintain the sustainable use of ecosystem goods, which also relates to risk management when sustainability is threatened.

Unknown impacts align with unknown risks, both factors of uncertainty that ought to be addressed by appropriate decision-making by means of setting new goals (objectives). As such, impacts and risks enhance the uncertainties of content (examining the issue) and organisation (informing and mobilizing people), called respectively cognitive and institutional uncertainty. Hence, systems uncertainty challenges and pushes policy and management to their outer limits, to meet existing or new goals (e.g., on sustainable development, climate mitigation, or risk avoidance). It is clear that goal attainment will be hampered when uncertainty is high, but also that setting objectives to respond to complex issues involves higher levels of uncertainty. "The imperative to reduce uncertainty is evident in the human experience" [57] (p. 15). Therefore, the aim of decision-making should be to manage uncertainty and complexity [29] and to reduce undesired impacts, rather than to eliminate them, which compares to the reduction of uncertainty from areas that are badly understood to the well-known area [58]. Policies are intended to achieve the goals [58] and policy principles_including, e.g., the precautionary and the polluter-pays principle - which are part of policies and instruments and a means to reduce uncertainty. This potentially requires knowledge innovation or institutional reorganisation. To the latter applies 'institutional uncertainty', with a highly fragmented institutional setting that results from decision-making in different places, and in different policy arenas in which actors from various policy networks participate [33]. We consider institutional uncertainty as emerging from structural complexity, increasing with the intensifying involvement of and interactions between actors. Actors, knowledge, and institutions compare with the three forms of uncertainty as defined by van Bueren et al. [33]: strategic, cognitive, and institutional.

Evidence. (1) Voulvoulis et al. [90] deal with the implementation of the WFD and the difficulties in shifting towards systems thinking. Wuijts et al. [91] point to the imbalance between policy and management with respect to the WFD that focuses on planning rather than on implementation, and the restraints of a legal framework leaving little adaptive capacity once set in place. Based on a literature review, Wuijts et al. [91] also indicate some shortcomings of the WFD and similar processes when relating responses to goals, impacts, 
and public participations. They plead for inclusive decision-making by stakeholders on priority setting and balancing a river's needs with other societal interests [91]. However, in general, policy implementation is quite slow, apparently because of the obstacles encountered in the transition process towards new management paradigms [32]. This combines the ACC-units (DecMak), (CAPs), (NatRes), and (SocOrg). (2) Maani [29] believes that cognitive uncertainty in climate change adaptation is exacerbated by the complexity of decision-making as a result of institutional uncertainty caused by an increase of the number of institutions involved, public demands and influences, and changes in policy, regulations, leaders, and staff. In this respect, the issue is raised of evaluations of collaborative policy-making in complex systems that are still based on the assumption that policies can be designed according to predictable outcomes [92,93].

\subsection{Contentual Complexity (ContComp)}

Concept. Contentual complexity is essentially about content, and is presented in this unit in conjunction with thematic integration. The basic idea is that many of the existing environmental impacts are well understood and can be explained by common knowledge (which is: to solve daily issues), that there is ample room to cross the thematic borders to deal with complex issues, but that knowledge and thematic issues become challenging when it is about 'wicked problems'. In the latter area, the point of indeterminacy is exceeded, and issues are characterised by unknown impacts, unexpected damage, and/or systemic risks. Contentual complexity has therefore two dimensions: roughly, the interactions within and between themes at the same level, and the broadening and exchange of thematic content across hierarchical levels. The first dimension includes horizontal management nexuses (e.g., water-agriculture-nature). To the second dimension applies vertical management such as biodiversity loss at a local and global scale. To both dimensions also apply learning concepts aiming for integrating knowledge.

Description. Content in an environmental context is considered a collective term for knowledge (theories, practices, concepts), opinions, descriptions, and methods that contribute to the understanding of a subject. Contentual complexity indicates the degree to which content is perceived as being complex. It is part of content-related management that describes the horizontal and vertical integration of content. Content includes thematic issues (i.e., related to, inter alia, environmental disturbances, actors' opinions, policies, societal issues) and knowledge (i.e., epistemological). Content management has two dimensions: horizontal (exchange of knowledge between disciplines, integration of policies) and vertical (connection of knowledge levels within a discipline, harmonisation of policies across hierarchical levels) management. Integration is the process that combines and describes both dimensions in order to determine the level of complexity. Issues are events that cause significant spatial or temporal impacts. They emerge at the points that boundaries of available knowledge are exceeded, calling for innovative theories, concepts, and practices. However, defining an issue means that it should not only initiate knowledge development (issue-driven science), but also adapted forms of management (issue-driven management), and adapted strategies between stakeholders (issue-driven strategies). In the case that an issue involves a large number of themes and integration of knowledge fails, it must be deemed a 'wicked' or complex problem. The wicked problems approach is an alternative to the linear, static, simplistic, hierarchical (top-down), and mechanical (step-by-step) model, and differs from conventional expert-driven and single-focus approaches, and decision-making with straightforward planning responses $[28,29,36]$. Rittel and Webber [82], who first described wicked problems, list 10 distinguishing properties: (1) they have no definitive formulation, (2) there is no stopping rule, (3) solutions are good-or-bad, not true-or-false, (4) there is immediate and no ultimate test of a solution, (5) every solution is a 'one-shot operation', (6) the whole set of solutions cannot be described, (7) every problem is essentially unique, (8) a problem can be considered to be a symptom of another problem, (9) discrepancies can be explained in numerous ways, and (10) planners are liable for their actions. Since most contemporary issues seem to meet this 
description, super-wicked problems are defined to indicate those that comprise the next four features [28] (p. 3): "time is running out; the central authority needed to address them is weak or non-existent; those who cause the problem also seek to create a solution; and hyperbolic discounting occurs that pushes responses into the future when immediate actions are required to set in train longer-term policy solutions". These features are connected to the following ACC-units, respectively: (RiskResp) (emergency), (GovInst, OrgMgmt, DecMak) (policies and instruments), and (RiskResp) (response needs vs. response effectivity).

Wicked problems suggest that there is a fundamental indeterminacy in the problems [37]. The scale designed by Walker et al. [58] shows five levels, ranging from determinism to indeterminacy: determinism, statistical uncertainty, scenario uncertainty, recognised ignorance, and total ignorance. The point of indeterminacy is indicative of wicked problems, representing 'total ignorance' that is described as "a deep level of uncertainty, to the extent that we do not even know that we do not know" [58] (p. 13). This point is reached when unknown impacts become issues exceeding the boundaries of dynamic functioning of complex systems. In this case, they act as drivers for exploring new and broader fields of knowledge. Since the abovementioned scale applies to model structures, it is considered a measure of 'systemic uncertainty'.

Evidence. (1) ES G\&Ss is an interesting topic to illustrate knowledge issues. Lautenbach et al. [26] analysed literature on ES G\&Ss and detected shortcomings with respect to social-ecological validity, trade-off analysis, off-site effects, stakeholder involvement, and relevance and usability. Learning across thematic boundaries of ES services is a means to avoid blind spots in knowledge and might help to reach the required level of interand trans-disciplinarity for multifaceted ES services assessments, resulting in both better science and improved management support. (2) Torres et al. [94] stresses the conceptual aspects and challenges of operationalisation that result from nexus thinking. In this respect, also Phan et al. [95] refers to the importance of conceptual model development by the identification of important system variables and their relationships in the system. Walker's indeterminacy-determinacy scale is consistent with the beforementioned Cynefin concept of Snowden. (3) Wicked problems include nearly all public policy issues and planning problems are inherently wicked [82]. Maani [29] calls climate change adaptation a wicked problem related to partnerships between stakeholders and social learning. It illustrates the first description of wicked problems: ill-formulated, with confused information, multiple stakeholders and decision-makers with conflicting values involved, and confusing systemic ramifications [36]. This makes it conceptually connected to the post-normal science of Funtowicz and Ravetz [25]. In the perspective of Rittel and Webber [82], wicked problems are opposite to 'tame or benign problems' that have the attention of most scientist and engineers. Tame problems compare with the 'clear domain' of the Cynefin concept (SystImp).

\subsection{Knowledge Domains (KnowDom)}

Concept. The unit 'knowledge domains' elaborates on the 'content' part of (ContComp) and is about the production and use of (and interactions between) different types of knowledge when dealing with thematic issues and (more) complex systems. Since wicked problems tend to cross the borders of common practices, issues relate to an array of disciplines, which requires advanced development and integration of those disciplines. With a larger number of knowledge domains involved, new concepts may be needed, grounded on solid theories and of practical use.

Description. Contentual complexity is dependent on the extent of the thematic issues and the availability and integration of knowledge. Knowledge domains include any classification of knowledge aggregation, as well as their interaction forms. Wuijts et al. [91] calls 'social-ecology' a knowledge domain. Environmental issues are drivers of science for they are thematically related to these domains by means of their natural components (air, water, soil, biota), societal capitals (economic, social, natural), natural resources (uses, ecosystem services), and processes (disturbances, governance, data/information cycles). 
In this paper, two different classifications of knowledge domains are selected: scientific disciplines to refer to the common categorization of knowledge, and the Kaiser-Fuhrer knowledge forms to address thematic issues. Scientific disciplines are categorised into four groups (formal, natural, social, and applied science) [96]. Other classifications discern between alpha, beta, and gamma sciences. Apart from this, Kaiser and Fuhrer [97] distinguish between four knowledge forms: declarative knowledge (explaining how systems work), procedural knowledge (the actions needed to achieve a goal), effectiveness knowledge (explains impacts by means of the effectiveness to reach a certain outcome), and social knowledge (moral and conventional social norms). With 'convergence', Kaiser and Fuhrer [97] address the need for knowledge integration across the distinct forms. These forms fit well within the ACCU concept in the way they relate to (DiscKnow) and (EIC) (declarative knowledge), to (ContCompl) (procedural knowledge), to (SystImp) (effectiveness knowledge), and to (ProbSolvStrat) and (SocOrg) (Social knowledge). Knowledge domains also include the development of new content areas by means of theories, concepts, and practices. Conceptualisation is a process in between practices (empiricism; tools, methods, and applications) and theories; operationalisation is the implementation process of theories that moves towards concepts [94] (p. 8): "without defining an area of application") and practices (e.g., case studies, experiments, and monitoring).

Evidence. (1) There is a wealth of concepts, terms, and definitions that cover the knowledge domains of water and other areas. At the beginning of the 21st century, Biswas [98] predicted an increasing complexity of water problems, becoming intertwined with a diversity of economic and social sectors. (2) Nowadays, there is a growing conviction that cross-sectoral co-ordination and knowledge integration is a necessity for organizing knowledge production for sustainability, which must be shared among actors by means of social learning processes [27]. Larson and Redman [99] apply the Kaiser-Fuhrer typology to water education programs. Schneiderhan-Opel and Bogner [100] and LaDue et al. [101] both elaborate on 'water literacy' — combining hydro-social knowledge and decisions on water-related, socio-scientific issues_amongst pupils or students.

\subsection{Disciplinary Knowledge (DisKnow)}

Concept. Disciplinary knowledge elaborates on the 'thematic integration' part of (ContComp) and on (KnowDom) and relates to these by disciplinarity levels and a reductionismholism axis. As a result, intra-disciplinarity largely combines with reductionism and trans-disciplinarity with holism. The unit illustrates that wicked problems (ContComp) associated with complex systems require a more holistic approach. On the other hand, there is always an area outside the acquired knowledge, offering a potential for emergence.

Description. Disciplinary knowledge-a term mentioned by Brugnach and Özerol [102] —is about creating new knowledge (emergence), integrated within existing knowledge across levels of disciplinarity on a holistic-reductionistic scale. Complex issues tend to involve a large number of cross-cutting themes (aggregation) and require a higher span of disciplinarity. The degree themes are aggregated and combined with theories and practices across the scientific disciplines determines the knowledge integration. This integration process is a counterweight to scientific reductionism, according to Buchanan [36], a process of fragmentation and specialisation that had already started by the end of the 19th century. However, knowledge integration is no longer restricted to scientific integration only, but is also fed with knowledge generated by non-academic actors (including governance and stakeholders), such as citizen science. This is termed knowledge co-production, a product of 'reciprocal learning' [102].

Knowledge integration covers any form of disciplinarity, as well as the process of social learning by stakeholders. Disciplinarity ranges from intra-disciplinarity (specialisation), multi-disciplinarity, interdisciplinarity (integration), to trans-disciplinarity (process functioning). Disciplinarity forms are located on different spots of the holism-reductionism scale that represents the range between generalisation and specialisation. Knowledge integration therefore aims to combine knowledge at different levels of analysis. It is 
supposed that contentual complexity requires innovation that goes beyond the limits of integration, of which knowledge emergence is the result, providing new insights to cope with contentual complexity. Referring to Buchanan [36], it can be stated that innovation results from framing existing concepts in a different setting, raising new questions and ideas. Knowledge includes science and research, expertise and experiences, as well as lay-knowledge. This makes (DisKnow) not only a matter of content, but also of participation. This conceptual enlargement forces to think about problem-solving strategies when dealing with environmental issues. At least transdisciplinary research has become part of post-normal science [103] and is discussed in another ACC-unit.

Evidence. (1) Braat [104] addresses the lack of knowledge of system dynamics and the dominating perception of a controlling form of environmental management. Voulvoulis et al. [90] argue that the complexity of catchment management within the WFD implementation requires interdisciplinary research and knowledge integration. (2) In 2001, the OECD concluded that the scientific knowledge about biodiversity was still deficient, facing substantial gaps that need to be filled prior to engaging in a conceptually sound outlook on biodiversity [52]. (3) One challenge of thematic integration is to improve the validity of social-ecological systems, combining the ecological validity of models with knowledge of social systems [26]. (4) The One Health concept addresses global health security and aims for an international, cross-sectoral, transdisciplinary approach at the interface between human, animal, and ecosystem health domains, from multiple perspectives (from environmental to social sciences) in order to identify risk drivers of infectious diseases [105]. (5) There is a need to cross the research areas that developed rather independently for a long time, and to include social learning of stakeholder groups [32]. (6) Nexus thinking is a more conceptual approach of disciplinarity integration, in which processes of subdomains are combined. Examples are the water-energy-food nexus, and the ecosystem-economic carrying capacity approach [20].

\subsection{Problem-Solving Strategies (ProbSolStrat)}

Concept. Problem-solving strategies explain the way to deal with societal issues, considering decision-making basically depends on a combination of (scientific) knowledge-driven and (social) value-driven science. Complex systems and issues are expected to be less supported by evidence-based science (increase of systems uncertainty) and more influenced by decision stakes. Strategies therefore range from a reductionistic, specialised scientific (fundamental and applied science) to a holistic, humanistic (post-normal science) approach.

Description. Physical ecological knowledge is supposed scientifically objective, prevailing in ecosystem management on the social aspects of management [103]. Ceola et al. [106] and Rist et al. [103] emphasise the growing need and recognition for using and integrating non-scientific, managerial, and societal local knowledge with scientific knowledge for research and management in a process of social learning. The selected paradigm that combines the social and scientific branch of management is the concept of Post-Normal Science (PNS) [25] for it applies to complex systems, in particular when integrating complex natural and social systems aiming for sustainability. It links epistemology and governance in combining facts and values into a single concept. PNS applies to cases with high levels of 'decision stakes' and 'systems uncertainty', and is therefore situated beyond 'normal' or applied science and professional consultation. The basic idea is that there is no clear distinction between hard, objective scientific facts (epistemic aspects) and soft, subjective value-judgements (axiological aspects), since-typically for issue-driven science-facts are uncertain, values in dispute, stakes high, and decisions urgent. The context of PNS is either policy-related research, science-related decision-making, or creative technical-social innovation. This results from the involvement of an 'extended peer community', consisting of both professional and lay people that have or wish to participate in solving an issue. PNS shifts from a reductionistic, analytical, and specialised worldview towards a systemic, synthetic, and humanistic approach. 
This unit is completed with two types of challenges that are met when applying ecosystem management approaches (as explained in (PubGovStyl)) [107]: one type is associated with defining the ecosystem bounds and contends with a lack of knowledge of ecosystem processes; the other type is about the degree of interactions with stakeholders, being complex and including potential conflicts with other management goals. These challenges are associated with, respectively, systems uncertainties and decision stakes of PNS.

In combining PNS and the challenges with the presented schema, issue-driven science connects to the environmental impacts. Factual input and ecosystem challenges are considered to be knowledge-driven; policy and stakeholder challenges are considered to be value-driven. Market environmentalism is a domain attempting to conciliate economic growth, allocation efficiency, and environmental conservation [4], and serves as a good example of combined knowledge/value-driven science. PNS is in between (DisKnow) and (PubGovStyl), in which the public involvement ('knowledge co-production') stands for the extended peer community. To illustrate the ambiguity of using knowledge, Wuijts et al. [50] note that scholars of different knowledge domains have different perspectives on the effectiveness of water governance approaches and hence interactions between them play an important role in achieving water quality ambitions.

Evidence. (1) The area of science-policy interaction is discussed by Brugnach and Özerol [102], referring to transdisciplinary research and knowledge co-production-the process of 'reciprocal learning', bridging knowledge among academic and non-academic actors - with on the one hand, science and disciplinary knowledge, and on the other hand, the stakeholders and actors of politics and power. As an example, Martín-López et al. [108] conclude that scientists should be cautioned to incorporate multiple values (biophysical, monetary) and multiple forms of knowledge (disciplines ranging from biophysical to socio-economic) in ecosystem services research in order to improve the environmental decision-making process. (2) Maani [29] calls climate change adaptation a wicked problem that requires collective learning, new modes of decision-making, and collaboration. Rutten et al. [109] offers an illustration of how complex adaptive systems are understood and used by ecosystem managers in practice, when applied to water management.

\subsection{Structural Complexity (StrucComp)}

Concept. Similar to contentual complexity, structural complexity has a horizontal and vertical management component, applying to organizational structure on the one hand, and to skills and competences on the other hand. The idea is that more intensive interactions between entities at the same level and/or between hierarchical levels will optimize the exchange of content between actors. This is facilitated by an optimised organisational structure. In addition, skills and competences will increase the capacity of an organisation. In the case of systemic risks or wicked problems, the result will be an increase of system entropy, requiring the organisation to increase its capacity ('capacity building'). Increase of structural performance is dependent on the available technological, human, and conceptual skills within an organisation.

Description. Structural complexity deals with organisational management. Organisational management includes the organisation structure, as well as the use and application of skills and competences to deal with content. This implies that (StructComp) is subordinate to and serves as a means of dealing with (ContComp). Organisation structure includes the entities of an institute, the interactions between entities, as well as the financial and human resources to make it operable. This unit includes the three organisational dimensions described by Corbett et al. [16]: leadership style, organisational culture, and institutional systems. These dimensions connect in several ways to the units (OrgMgmt), (PubGovStyl), (GovInst), and (ProbSolStrat).

Organisational management combines horizontal and vertical management and seems to switch in complex systems from line management to some form of network management. Horizontal management deals with co-operation at the same hierarchical level within (co-operation) or between (e.g., cross-sectoral initiatives, stakeholder participation) organi- 
sations; vertical management deals with the hierarchy between organisational levels (e.g., linear top-down hierarchies). Vertical structural and contentual management are balanced in the sense that hierarchical levels of an organisation should not hamper development or transfer of knowledge between levels; horizontal structural and contentual management are balanced on the condition that knowledge development and exchange are according to the available skills and competences.

Organisational structures are under pressure when significant impacts/effects occur or risks are expected, and /or R\&D calls for urgent solutions. Then business-as-usual (BAU) cannot be maintained; instead, adapted forms of management are required. Institutional changes are challenging inter- and intra-institutional interactions, as well as the equilibrium between research (knowledge generation and application) and management (institutional organisation), both depending on the same human and financial resources, which makes them factually competing.

With institutional responses depending both on the feasibility to take measures and on contentual complexity, structural complexity becomes to a large extent a matter of spending financial and human resources to enhance knowledge on the one hand, and to adapt to institutional changes on the other hand. In terms of organisational management, this is basically about the allocation of resources to institutional and personal competences and skills. 'Personal skills' fits the "three areas of skills" — technical, human, and conceptual—as described by Hersey et al. [110]. Those skills apply to any individual to a different degree, acknowledging 'technical skills' has become a rather restricted term nowadays. It is now proposed to apply this to any organisational level, including authorities and stakeholders. The need of current environmental challenges to combine technical solutions with good governance [42] is partially reflected in the unit by the combination of technological and human skills, presuming human skills facilitate integration and a common understanding of environmental governance. In this sense, Romano and Akhmouch [15] distinguish between technical (e.g., planning, quality information, monitoring, and evaluation) and human resources (e.g., staff, expertise, and managerial capabilities) gaps when discussing capacity—a key governance gap-in urban water management.

Human and technical skills are essential to and combined in conceptual skills. Conceptualization in this paper deals with a mixture of strategic thinking and problem solving, and of developing theoretical/practical and holistic/reductionistic approaches. The opinion of Biswas [98] on IWRM that concepts, to have any validity, must be implementable to find better and more efficient solutions, seems also applicable to organisational management. This means that, if increasing structural complexity requires additional resources, the challenge is to identify the required human and technical skills and to allocate financial and human resources accordingly. This leads to the conclusion that the technical/human management ratio $(\mathrm{T} / \mathrm{H}$ ratio) is not a voluntary choice, but dependent on the issues at stake. Within the context of institutional structure, public administrations are mainly vertically structured and featured by an executive, linear, top-down (command-and-control), value-driven approach. Scientific institutes tend to be horizontally oriented, featured by project management (aiming for innovation) and a network-structured, co-operative, and evidence-based approach. Hence, the $\mathrm{T} / \mathrm{H}$ ratio depends on the available financial and human resources, but determines in its turn the inter- and intra-institutional organisation structure. The degree to which these are combined has been denoted by an array of governance styles (PubGovStyl).

To some extent, the $\mathrm{T} / \mathrm{H}$ ratio also reflects the distribution of power between 'technocrats' and 'bureaucrats' within an organisation, and as such the potential of both groups to influence decision-making. Within the context of organisational management and leadership, policy-makers are suspicious about complex models whereas river basin modellers consider aquatic modelling as a necessity [32]. In a similar way, issues dealing with relationships between environmental and economic policies tend to shift discussions from facts to values when facts become more uncertain [103]. More efficiency and effectiveness could be obtained when mixing content and structure in a project-management approach. 
Organisational structures are designed according to the social interrelationships between their participants. This creates social energy, which some consider a part of capacity, as important as skills and resources [31]. Capacity itself is an emergent property of systems, based on individual competences, group dynamics, collaboration, and joint performances [31]. Capacity has also been defined by UNDRR in relation to 'risk' as "The combination of all the strengths, attributes and resources available within an organization, community or society to manage and reduce disaster risks and strengthen resilience" [111].

If the point capacity-indicated by the intersection of horizontal or vertical management, or the combined skills/competencies and resources-fails to address the wicked problems or systemic risks, it leads to an increase of system entropy. Morgan [31] indicates that many systems exhibit entropy. In addition, Pahl-Wostl [17] (p. 355) defines 'adaptive capacity' as "the ability of a resource governance system to first alter processes and if required convert structural elements as response to experienced or expected changes in the societal or natural environment". In this sense, adaptive capacity links institutional capacity with dynamic governance styles.

Evidence. (1) Structural complexity as a result of contentual complexity was noticed in 2001 by Biswas [98] (p. 248): "many of the water problems have already become far too complex, interconnected and large to be handled by one single institution, irrespective of the authority and resources given to it, technical expertise and management capacity available, level of political support, and all the good intensions". This "sectoral fragmentation of water-related tasks across ministries and agencies" is termed 'policy gap', one of the seven key implementation gaps in water policy [1,13]. (2) Uncertainties arising from global changes and climate change are challenging natural resources management and new approaches of risk management require transformation processes in institutional regimes and management style [32]. (3) For this reason, sustainability is likely to be the ultimate goal in future for societal development. Sustainable development, as part of the societal process, results in quantitative and qualitative changes in the interactions between social actors and societal structures [103]. (4) Considering integrated water management and sustainable development in the UK and USA, Howsam et al. [112] (p. 35) conclude that "many institutions still have structures which do not encourage integration".

\subsection{Public Governance Styles (PubGovStyl)}

Concept. The 'public governance styles' unit deals with the way public authorities involve stakeholders in governance participation, combine structural and contentual complexity in terms of horizontal and vertical management, and in- or externalise content and structure. Management has two orientations: environmental management (contentoriented) and governmental/institutional management (structure-oriented). In- and externalisation are mutually dependent on each other. It explains, inter alia, how including complex environmental issues in decision-making results in administrative reform, or how administrative restraints are at the basis of thematic/contentual externalisation. There are basically two ways: a change of content causes a change of management (content-driven changes), and a change of (organizational) management results in a change of content (managerial-driven changes). It can be observed that current global developments force towards internalisation, shifting governance styles from conservative to dynamic.

Description. This unit further elaborates on horizontal and vertical management, in the sense that it shows the interactive processes between content (ContComp) and organisation structure (StructComp) in terms of internalisation and externalisation. At the basis is the observation that (public) authorities gradually shift from a conservative to a dynamic style, with new or different content and an adapted management style. It is hereby supposed that new content (resulting from crises, complex issues, public interests) forces authorities to be included in the decision-making process. This process of thematic (content-driven) internalisation also requires structural (managerial-driven) internalisation (e.g., citizen participation, management boards). In the opposite case, contentual and structural externalisation (e.g., privatisation, 'core business' management) are combined. 
The shift from a conservative towards a dynamic governance style compares to some extent to a shift from intra- to trans-disciplinarity (DiscKnow), or according to Habermas' theory of communication, from strategic to communicative actions.

Contentual and structural internalisation is about expanding environmental and/or organizational management to other issues and/or with other societal organizations involved, aiming to enforce communication with and support from stakeholders, often in more informal settings and breaking through hierarchical levels. Numerous 'styles' have been developed over the last decades. Most of them tend to apply to the intermediate process modes 'content-driven' and 'managerial-driven', between the end-points 'conservative' and 'dynamic'.

Governance can be simply described as "a decision-making process that drives the relationship between social institutions and the public affairs of a given society" [113]. Public governance styles (modes, regimes) show a variety of approaches (strategies), which have still been differentiating at a high pace over the last decades. They are hard to categorise as they show a mixture of features: content- and/or managerial-driven, leadership style, organisational structure, degree of co-operation and multi-level approach, objectives, etc. In this sense, scholars often consider three 'modes': hierarchical (bureaucratic hierarchies), market, and network governance $[15,17,35]$. Environmental governance includes all kinds of measures to prevent, reduce, and/or mitigate harmful effects, in order to respond to the growing concern about environmental degradation, resources depletion, biodiversity loss, and climate change; hence it stands for interventions aiming at changes in environment-related incentives, knowledge, institutions, decision-making, and behaviours [114]. Governance is not a static equilibrium, but rather a continuum of shifts that indicate changes in the role and power of all actors involved. This results in a large number of conceptual labels that characterise new governance and management arrangements in terms of, e.g., participation (e.g., partnerships), regulation, transition, and adaptation. [114]. Corbett et al. [16] relates this differentiation in styles to differences in public services and organisational structure, distinguishing between fully, partially, and non-routinised systems. According to Pahl-Wostl [17], new government modes and knowledge generation are needed to deal with increasing uncertainty and complexity. Gupta and Pouw [6] defend the idea that socio-ecological issues require multi-level governance strategies and mutual exchange between bottom-up and top-down approaches. The proposed governance styles unit distinguishes between four subunits: governance and institutional management (mainly managerial-driven), environmental management (mainly content-driven), conservative governance (content- and/or managerial-driven, showing externalisation), and dynamic governance (content- and/or managerial-driven, showing internalisation). In addition, there is an intermediate governance style with no outspoken characteristics. Mapping some of the approaches described in literature results in the following characterisation of governance styles:

1. Conservative:

i. Managerial-driven: Bureaucracy (in terms of Max Weber), Command-andControl (CAC), New Public Management (NPM) [115];

ii. Content- and managerial-driven: Command-and-Control resources management (CACRM) [21,52];

2. Dynamic:

i. Managerial-driven: Network management [33], Networking Governance, Collaborative governance [116];

ii. Content- and managerial-driven: Community-based natural resource management (CBNRM) [107]; Sustainable Governance, Adaptive Governance [17], Deliberative Governance [115], Inclusive Water Governance [14];

3. Governance and institutional management:

i. Managerial-driven: New Public Governance (NPG), Regulatory Governance [117], Multi-level governance [115]; 
4. Environmental management:

i. Content-driven: Natural Resources Management (NRM), Integrated Water Resources Management (IWRM), Ecosystem-Based Management (EBM) [118], Ecosystem Approach (EA) [107].

According to the OECD [52], most environment-related legislation was focused for a long time on command-and-control measures that imposed restrictions with little flexibility, although a combination with market-based instruments seems now to be more effective. Resources management in general, as well as water management and governance in particular, have a tradition to be ruled by a command-and-control management approach, with narrow stakeholder participation, a dominance of governmental actors, and little supportive of social learning. However, the complexity of environmental problems and human-technological-environment systems calls for new, more systemic approaches, rooted in knowledge co-production and acceptance of uncertainty. [17,27,32]. The same command-and-control models apply to policy-making, whereas sustainable development involving stakeholders requires relations based on communication, deliberation, and negotiation [103]. This is supported by the description of 'network management', including "the fulfilment of roles of facilitator, broker, and mediator and efforts to reach agreements between parties involved in the goals, structure, and rules of the policy game" [33] (p. 197).

Surveying the dynamics in these areas makes clear that current developments in water governance indicate a transition from a bureaucratic (in terms of both a 'top-down' bureaucracy and an implementing form of CAC resources management) to a co-operative style (in terms of both sharing decision-making and knowledge exchange). CAC resources management includes many measures intended to protect and conserve natural capital, but imposes restrictions with little flexibility, and tends to be economically inefficient, costly to enforce, and inflexible [52].

The conservative and dynamic styles are dominated by, respectively, an internal and a combined internal/external public organisation structure. Conservative means that content, and hence roles and responsibilities, as well as the organisational structure are determined and remain more or less constant. A straight implementation of government policy tends to be conservative. The more dynamic, the more content will be added to the discourses, changing roles and responsibilities of authorities, and the institutional organisation. Discussing water issues with stakeholders in workshops or river basin committees fits within a dynamic style. Different styles may apply to the same organisation, as it can be expected that policies dealing with levies, law enforcement, and permits are better served with CAC. It is understood from Rist et al. [103] that the way to deal with natural resources needs a shift from management to governance through transdisciplinary work, ideally contributing to the social learning approach on a distinction between forms of social interaction, as suggested by Jürgen Habermas. In terms of Habermas's theory of communication, the 'governance styles' compares with the transition from strategic actions to communicative actions, or-according to Rist et al. [103] — with a shift from government to governance-based policy-making. The latter reflects the increasing involvement of participants, and increased content-complexity tends to raise structure-complexity (less bureaucracy, more adaptive governance).

In- and externalisation mark the differences between internal and external practices and correspond with the distinction between internal and external governance (according to the definitions of the OECD [117]), or between the internal and external policy environment [16]. The distinction made by Corbett et al. [16] is at the level of a single authority, with internal regulations and practices that are easier to change, and external rules imposed that are less susceptible to change. From the governance perspective, internal stands for public authorities, and external for stakeholders. Important to adaptive governance is social learning, involving interactions with stakeholders that both serve knowledge exchange and implementation support, and as such are essential for governing socio-ecological systems in times of abrupt change [17]. 
Public governance styles are the extension of problem-solving strategies (ProbSolStrat) in the sense that they both deal with the integration of science and governance, but the former (PubGovStyl) outweighs the latter as governance is decisive in formulating actions. Practice, however, is different. Water management is, in most European countries, largely based on expert knowledge guiding management decisions and not on a participatory approach [32]. Aiming for sustainability, expert knowledge should be complemented with the participation of societal groups in the decision-making process as they are the ones that are affected by and are expected to support and implement the decisions. Borowski-Maaser et al. [116] argue that collaborative governance must be embedded in existing governance structures and link to decision-making to be effective.

Evidence. (1) There is a plea to align local and regional water management with integrative river basin approaches, embedded into a perspective of global change [32]. Therefore, several authors indicate that the need for IWRM or governance change-which is called adaptive capacity - follows the developments in river basins with changing patterns of water demands or water availability that result from socio-economic developments, and that the institutions should be designed accordingly $[119,120]$. According to Akhmouch and Correia [13], the fundamental reason for adapted water governance is that all socioeconomic sectors depend on water, which makes water policy and management tightly interwoven with all sectors, making it necessary to promote some order, to settle conflicts and to manage trade-offs among various conflicting uses. (2) Biswas [98] notices the need for water policies and water-related issues to be assessed, analysed, reviewed, and resolved within an overall societal and development context, in order to avoid not achieving the main objectives of water management aiming for improved well-being. (3) Adaptive governance complexity was experienced in India where the introduction of models of integrated river basin management as designed by the developed world did not meet the real societal issues of a developing country related to hydrogeology, demography, socioeconomics, and the organisation of the water sector [119,121]. This is supported by the study of Schulze and Schmeier [120], which concludes that the adaptative capacity of river basin organisations (RBOs) largely depends on its membership structure, functional scope, and data and information management mechanisms, which is, according to the PTM, respectively, the (SocOrg], (ContComp] related to (CAPs), and the (EIC). (4) In the case described by Wuijts et al. ([50], existing governance approaches prevail and seem therefore not effective in attaining the WFD water quality ambitions since they are not addressed in the scientific and policy debate. In this case (ProbSolStrat), (PubGovStyl), (GovInstit), (OrgMgmt), and (DecMak) are concerned. (5) Innovative technologies are considered key to systemic change, the transitions not being able to be planned and organised by top-down governance that, instead, "will rely on much more uncertain, emergent processes of experimentation and learning" [122] (p. 22). Innovative approaches are a necessity for supporting sustainable strategies in dealing with complex socio-environmental problems [32]. (6) Adaptive (water) management is adaptive for it contributes to a better understanding of processes and interactions, and it includes a learning process of which the outcomes are continually improving management policies and practices [32]; it is managerial in the sense it is polycentric, balances between bottom-up and top-down processes, and includes a broad representation of stakeholders, experts, and bureaucrats in developing and using domain-crossing scientific and lay knowledge [27]. (7) Co-governance, as applied by Borowski-Maaser et al. [116] to the EU Water Framework Directive, evaluates processes that relate to stakeholders' involvement (SocOrg), (BenPowInta), governance structures (GovInst) and decision-making (DecMak), knowledge integration (ProbSolvStrat), and different levels of governance (panarchy in (AdCycl)). (8) Romano and Akhmouch [15] argue that urban water management requires expertise from different fields and the capacity to respond to emergencies, to set up measures, and to carry out duties, all to be implemented according to citizens' needs and in co-ordination with other policies and sectors. 


\subsection{Governance Institutions (GovInst)}

Concept. This unit considers governance institutions the physical or organisational bodies, along with their structure, which is different from the governing of actors' behaviour by means of social rules, as denoted in social sciences [17]. In this unit, roles and responsibilities of an institute are balanced against its organisation, recognizing-according to Romano and Akhmouch [15] - that the role of central governments in urban water management is more prominent in policy-making and regulatory functions, whereas local governments have a more operative role. The governance level is reflected in the institutional organisation. It is furthermore expected that institutional roles reflect the power range they acquire as an actor and that responsibilities counterweigh accountability and transparency. Accountability and transparency are principles of 'good governance' and important to engage stakeholders to contribute to sustainable water management [35]. However, since both stakeholders and institutions have their own strategy, strategic uncertainty is expected to increase with the number of actors involved. The combination of organisation and 'roles and responsibilities' results in a mosaic of separated (decentralised) or aggregated (centralised) institutions at different levels of hierarchy, each having a different power capacity.

Description. In general, the roles and responsibilities that are allocated to or acquired by governance institutions is according to the political powers and depending on their societal role. In contrast to industrial enterprises that tend to expand and that are internally organised, public authorities are separated and hierarchically concatenated from the local to the global level. Governance arrangements between state, market, and civil society may be different depending on the governance level, each level applying a different (centralised, decentralised, interactive, public-private, and self-governance) mode [114]. The institution's responsibilities and accountability are the exponent of the power capacity that results from the power sharing between actors involved. Institutional responsibilities and accountability describe the tasks and deliveries of an institutional body, but also cover properties such as effectivity, goal compatibility, transparency, and power dominance. Pahl-Wostl [17] mentions these properties are important to understanding governance failures, drivers, and barriers for change. We consider these as part of strategic uncertainty. Governance failures are denoted by the OECD as 'gaps': the funding (or fiscal) gap (i.e., the mismatch between administrative responsibilities and available funding), the capacity gap, the policy gap (i.e., the sectoral fragmentation of water related tasks), the administrative gap (i.e., mismatch between hydrological and administrative boundaries), and the information and accountability gaps [1].

Institutions are balanced in terms of power capacity that represents their responsibilities and the type and degree of structural organisation. Structural organisation includes the governance levels (e.g., multi-level governance), degree of power centres (e.g., polycentric systems), and the degree of their interactions (e.g., linear, web-structured). Highly centralised (monocentric), linear structures look the most promising in terms of governance efficiency and effectivity. Pahl-Wostl [17] mentions in this respect that involving actors in the participatory process contributes to compliance and effectiveness, but this may come at the expense of efficiency as this is more resource consuming. Additionally, complex systems have a higher degree of redundancy, whilst redundancy decreases efficiency. However, polycentric systems - and by extension CASs - are assumed to have a higher ability to change environmental conditions and to be less affected in their integrity by sudden changes of failures, applying their potential of self-organisation [17]. In this respect, Pahl-Wostl [17] points out the similarities with ecological systems, in which a higher diversity positively relates to maintaining functional integrity when conditions change. It is noted by Rist et al. [103] that social learning and sustainability need institutions and structures to change from a unilaterally improving process to one with the focus on transformation, innovation, and creation of new intra- and inter-institutional and structural arrangements. In the figure, this is designated 'institutional organisation', embodying both physical and organisational arrangements and related processes. Any change in societal organisation, governance, or organisational management, triggered by, for instance, 
environmental changes, may lead to adapted societal, institutional, or managerial forms. In this respect, adaptation compares to uncertainty: high levels of uncertainty may require far going adaptation, and vice versa. Institutional reform represents the level of high strategic and/or institutional uncertainty and institutional changes are likely to take place when disturbances reduce systemic limits towards critical points (SystVal). Reform is hereby understood as a reorganisation within the structure of the system, and transformation as a reorganisation of the system(s) involved. According to Boik [57], reform aims to limit damage and vulnerabilities and improve capacity and conditions, whereas transformation involves deeper repair and regeneration and fundamental reorganisation.

Governance institutions, both in terms of responsibilities and accountability and organisation structure, are balanced against the power interactions of all actors involved and the governance styles unit.

Evidence. (1) There is no clear option whether authorities should be more aggregated or disaggregated, but it becomes clear that institutional organisation must be according to the policy objectives intending to solve the environmental issues. A mapping of institutional roles and responsibilities of countries is performed by the OECD, discussing the role of ministries, public agencies, and local actors [1]. (2) The governance structure is strongly influencing multi-party cooperation and social learning processes [17]. Biswas [98] (p. 254) describes the difficulties of integrated water resources management with respect to institutional and organisational management: "In the real world, integrated water resources management, even in a limited sense, becomes difficult to achieve because of extensive turf wars, bureaucratic in-fighting, and legal regimes (like national constitutions) even within the management process of a single resource like water, let alone in any combined institution covering two or more ministries which have been historic rivals. In addition, the merger of such institutions produce an enormous organization that is neither easy to manage nor control." He also warns of the drawbacks of institutional integration, as it is likely to produce more centralisation and reduced responsiveness. (3) This is well illustrated by Bandaragoda and Babel [119] with a number of cases in Asia showing issues of institutional fragmentation and related inefficiency, lack of power, executive functions, and responsibility sharing and allocation. Institutional fragmentation, with overlapping mandates and conflicting goals that may lead to inadequate co-operation across authorities and water-related sectors and scales, is considered a barrier for stakeholders' engagement [14]. (4) After having experienced several cholera outbreaks, one important result of the 19th $\mathrm{C}$ sanitary revolution in London was the call for institutional reform [9,123]. (5) With the focus on river basin organisation, Bandaragoda and Babel [119] conclude from a number of Asian cases that higher level institutional reforms were found to be more difficult to achieve than reforms in the irrigation sub-sector, and they even noticed a paradigm shift from ecosystem management to institutional reforms of the water sector as a result of growing international interest in water.

\subsection{Societal Organisation (SocOrg)}

Concept. Societal organisation describes the way our society is structured and social groups interact with each other. Interactions result in partnerships between the actors involved: public authorities, the civil society, and the private sector. The role these stakeholders play is according to their societal features: interests and ambitions, norms and values, empowerment, and participation.

Description. Societal organisation depends on the aggregation of individuals into groups (actors) according to different hierarchies. Referring to Iribarnegaray and Seghezzo [113], citizens are located at the centre of the unit and considered individuals that can be actors in the process in different ways. Akhmouch and Correia [13] distinguish between: (i) levels of civil society, (ii) authorities, and (iii) associations and organisations. In combination with Driessen et al. [114] and Maani [29], this results in the following groups with respect to social life, the economy, and governance:

1. Civil society (public stakeholders, the people): citizens, communities, organisations, civil society. Civil society is the domain of associational life above the individual 
and below the state, consisting of linked networks through which groups pursue goals [30];

2. Private sector (private stakeholders, the market, business, and industry): citizens, businesses, federations-associations-corporations, (socio-) economic sectors, private sector;

3. Authorities (the state, governments): citizens, local—regional—national/state -international authorities.

This unit includes the formal (legal rules of administrative structures) and informal (social rules including cultural norms, values, worldviews, and attitudes) institutions as denoted in social sciences $[17,113]$, indicated with 'norms and values'. This strongly compares to the definition of social capital by Máñez et al. [30] (p. 10): "the relationships, networks and shared norms and values that qualify and quantify social interactions". At present, management of public affairs is based on norms and rules for the designation of natural resources and the social relations between actors. Different actors rarely share the same norms and values, and show unequally distributed powers, which cause conflicts about natural resource use and hinder sustainable development. Internal power is also dependent on external power. Empowerment challenges power relations between citizens and state, and focuses on empowering less powerful voices [27]. OECD Principle 10 [124] promotes stakeholder engagement and recommends avoiding power and expert/non-expert imbalances. Participation of actors in general, and social learning in particular, seems to contribute to a critical revision of norms and rules, and power relations and distribution when dealing with natural resources use or sustainability. Additionally, power issues dealing with natural resources use allow us to better perceive the link between knowledge and power. [103]. We now assume this also applies to financial and human resources within or between the social groups, making the societal organisation unit adjacent to (BenPowIntera), (PubGovStyl), and (ProbSolStrat).

The society shows, as a complex adaptive system, a number of 'societal features' that are considered drivers of the communication process between actors to deal with the 'complexity issue':

1. Interests and ambitions: the reasons actors show initiative, depending on their societal role;

2. Norms and values: the rules and beliefs of the actors to secure their interests; they include the 'universal human values' of Schwartz [125];

3. perceptions: include worldviews and mental models [29]; in between the two previous features. Policy is considered complex and unstructured because actors have different perceptions and interests [33];

4. participation: the degree of involvement of stakeholders in public governance (multiactor dialogue), and of which 'social learning' is one product of communication between societal groups;

5. Empowerment: the enforcement of the stakeholders' power, following co-operation with authorities.

The inner circle of the unit represents 'partnerships' in the sense of "voluntary but enforceable commitments between public authorities, private enterprises and civil society organisations" [30] (p. 13). Participation and empowerment are means of extending the space for communicative action in the area with prevailing strategic action [103]. Akhmouch and Clavreul [14] consider engagement as being developed from participation and apply the OECD typology that distinguishes different levels of stakeholder engagement, ranging from communication to co-decision and co-production. Increasing engagement of actors is expected to enhance 'strategic uncertainty' as they have different perceptions of the problems and its solutions, which may be the cause of diverging and conflicting strategies [33]. We also expect that this type of uncertainty relates to dynamic forms of (PubGovStyl). This aligns with the idea that Habermas's area of 'strategic actions' is the most 'strategically certain'.

Evidence. (1) There are numerous examples of interactions between civil and private stakeholders and public authorities. Influences of the external on the internal governance area include, inter alia, informing, lobbying, and even corruption. Interactions between the internal and the external governance area include participation, for instance by means 
of water management boards, and the involvement of global NGOs in discussion fora. (2) Iribarnegaray and Seghezzo [113] believe that contemporary governance draws more attention to the values, norms, and principles that underpin decision-making, and by which individuals play a more central role in the process. A more practical example is the selfmonitoring of waste-water and environmental reporting by industries in consultation with public authorities, leading to a change in responsibilities for monitoring from authorities to industry [126]. More structural in this respect was the privatisation in water governance of the hierarchical bureaucratic governance regime that shifted towards market-based approaches over the last century [17,35]. (3) Rist et al. [103] consider participation of actors in social platforms where multi-actor dialogues take place an essential part of transdisciplinarity. Here too, the afore-cited 'network management' [33] applies. The benefits of stakeholder participation in the decision-making process are: (i) acceptability and sustainability, (ii) social equity and cohesion, (iii) capacity and knowledge development, and iv) economic efficiency [14]. (4) Mental models, one of the Iceberg Model levels [29], illustrate the actors' perceptions in societal organisation. One example is given by Reed ([127] who advocates for shifting 'building' (construction) from conventional practices to sustainability, and further forming of 'regeneration' that aims to reconnect with the history of locales and natural processes within a 'whole system understanding'. (5) Boik [57] considers Schwartz's human values core needs that are important for a society's vitality (see: Fs\&Us in (CAPs)).

\subsection{Organisational Management (OrgMgmt)}

Concept. Management within the organization is crucial to implement decision-making and to secure institutional functioning. Leadership has a central role in controlling structureand content-related managerial processes. Structure-related managerial functions include organisation, planning, motivation, and control. Content-related managerial functions are production, implementation, innovation, and integration. Combined, their interactions secure the organisational functioning. The managerial processes detail the 'roles and responsibilities' and 'institutional organisation' described in (GovInst), act as the machinery behind decision-making (DecMak) and depend on the capacity of the organization (StrucComp).

Description. Organisational management serves as a tool that combines decisionmaking (mainly contentual) and institutional functioning (mainly structural). Both decisionmaking and institutional functioning require competent leadership to be efficient and effective. Leadership is considered central to management, in terms of both (identifying and valuing) content and (steering) processes. This ACC-unit therefore only shows a cartwheel that indicates the role of leadership (managerial functions) within an organisation as a steering point of content- and structure-related interactions. These interactions are expected to secure the organisational functioning. Although this also applies to any individual or group of individuals, these lower levels of aggregation are not further envisaged.

The content-related managerial process refers to Ichak Adizes' organisational structure of social systems [110], encompassing production, implementation, innovation, and integration. Applied to environmental organisation, this means:

1. Production: To public authorities, production means achieving goals (e.g., the Millennium Development Goals or the Aichi Biodiversity Targets) by producing content by means of output and outcome. In a more structural way, it also includes co-creation (co-production) in the sense of (1) interactions between public and private agents (public service co-production) and (2) the outcome of iterations between producers and users of knowledge aiming at increasing the usability of information or knowledge to support decision-making (sustainable science co-production) [27];

2. Implementation: making content part of the process;

3. Innovation: creating new content;

4. Integration: making content unique. 
The structure-related managerial process also includes the leadership's functional role and relates to the managerial functions of any organisation or level of the management process [110]: organisation, planning, motivation, and control:

1. Organisation: bringing together human, financial, and technical resources in the most effective way to accomplish the goals;

2. Planning: setting goals and objectives for the organisation and developing a process to get them accomplished;

3. Motivation: determines the levels of performance of the employees;

4. Control: ranges from personnel to process control. We consider 'evaluation' a broader and less direct form of 'control' when applied to processes. Control also reflects the type of leadership, with 'command-and-control' on the one side and mutual learning on the other side. Shifting from the one to the other side is an overall trend observed when systems complexity increases [32] and is one element of the overall adaptation process that transition requires.

In our study, these functions are expected to apply to any person (self-management) or organisational subsystem, and considered essential to leadership within public authorities. Leadership is central to both approaches and a cornerstone of decision-making. It is considered key in emerging and successful relationships of collaborative and cooperative natural resources management [35]. The type of leadership-e.g., directive or facilitative-characterises the form of management. It influences the balance between horizontal/vertical management, e.g., line/project management shifts or in-/externalisation of content. This also means that frictions are likely to occur if decision-making is not aligned across the management levels within an organisation or between organisations. According to Akhmouch and Correia [13], tensions unavoidably occur among authorities, or among authorities and the civil society, but it is the way those tensions or conflicting situations are overcome and settled that marks the quality of governance. They state that, therefore, all authorities have a recognised legitimacy at a given level, relevant to the formulation and implementation of water policies.

Evidence. (1) The creation of policy processes, institutional arrangements, and natural resource management practices to achieve sustainable and equitable resource use outcomes is a change process that demands rigorous evaluation, making it critical that policy makers, project managers and water board practitioners dispose of methods to effectively evaluate their natural resource management initiatives in a systemic way [128]. (2) Commons Transition [129] is an illustration of sustainable societal change by means of co-production with authorities, public and (small) enterprises involved. (3) Incorporating evaluation in adaptive co-management is considered essential to identifying changes, supporting adaptation, and enabling progressive learning at different levels of governance $[93,128]$. (4) Participants of a study on sustainable urban water management [35] considered leadership at the organisational, inter-organisational, and political levels important for setting the direction and vision and encouraging stakeholders to support the vision.

\subsection{Benefits/Power Interactions (BenPowInta)}

Concept. This unit represents an 'archetype of systems dynamics' (see: [31]). It explains how the amount of power of all actors involved (power capacity) is shared (power sharing) according to their mutual interactions (interaction forms). Power can be gained by or allocated to someone and is expressed as the share of natural, human, and/or financial resources (such as physical goods, skills, budgets). The amount of resources is a measure of the benefits owned, such as well-being, welfare, or even more power. The importance of this unit is that interactions between actors may change (e.g., stakeholder empowerment), causing a cascade of effects, including the shift to a different governance style.

Description. Individual and group power-aiming for leadership and/or resources maximization - is probably the strongest driving force between actors (public authorities, private sector, citizens). Power means benefits in terms of resources, social status, decisionmaking, etc., that contribute to well-being, welfare, or power itself. As such, 'benefits' are 
the result and show the allocation of resources to actors according to their power. More power stands for gaining benefits and hence securing or improving the conditions of the proper environment, be it societal capitals, governance institutions, or stakeholders. Power sharing is shown as a reciprocal interaction between power capacity and interaction forms. Power capacity is the potential of goods and services one can dispose of, including natural resources, financial means, and human skills. Power capacity of one actor can be low (L), medium (M), or high $(\mathrm{H})$ compared to another one. The term 'power interactions' indicates the process of sharing power among actors according to the amount of power available and the way actors behave. These types of interaction are well described in literature in a variety of ways, but are not fundamentally different. Interaction forms between two or more actors indicate their relative position and strategy, and hence the amount of power they (potentially) gain. An actor's attitude can be indifferent ( 0 , 'not interested'), positive $(+$, 'wants it'), or negative (-, 'doesn't want it') with respect to a particular resource. In practice, numerous actors can be involved, but in the most simple case only two actors are interested in the same (amount of) resource, their interaction form is not co-operative $(+,+)$, but competitive $(-,-)$. Therefore, interaction forms not only express the actors' own interests but also their strategy with respect to the other in the way their interests can influence each other and change in a positive $(+,+)$ or negative $(-,-)$ sense, or remain stable. The result is a set of $0 /+/-$ combinations of participating forces. A number of terms can be used from socio-biology, describing interactive forms between individuals or groups of organisms with respect to the availability of resources. These terms also apply to human and financial resources within a society or organisation, as such determining its power capacity. The interaction forms can be defined as follows (based on ecological definitions by Ricklefs [130], Stiling [131], and Holmes [132]):

1. Co-existence: $(0,0)$ : the occurrence of two or more (groups of) individuals in the same organisation in which no one benefits or is harmed;

2. Mutualism: $(+,+)$ : a relationship between two or more (groups of) individuals that benefits each of them;

3. Competition: (-,-): an interaction that occurs when two or more (groups of) individuals use or defend a common resource that is in short supply (exploitation competition) or when they harm one another in seeking a common resource (interference competition), hereby reducing the availability of that resource to each other;

4. Parasitism: $(+,-),(-,+)$ : an interaction between two or more (groups of) individuals in which some benefit and others are harmed;

5. Commensalism: $(0,+),(+, 0)$ : an association between two or more (groups of) individuals in which some benefit and others are not affected;

6. Amensalism: $(0,-),(-, 0)$ : a form of antagonism or competition between two or more (groups of) individuals in which some are inhibited and others not.

The described forms of power interactions also apply to the possession or beneficial use of goods in terms of public/private, (non-)rival, and (non-)exclusive (see: [52]). We consider benefit interactions to include power interactions. Mutualism and competition are the most extreme forms of interaction in terms of power sharing, reflecting conditions of collaboration and separation respectively. Power interactions-in terms of power asymmetries between stakeholders and power decentralisation - gain attention in papers dealing with water and climate governance (see: [102]). However, it seems more appropriate to speak about power (im)balances and shifts as there is no reason to equally share or distribute power. Instead, power must be shared and should be allocated to stakeholders (including governance) according to the different power modes that require decision-making for a particular issue or executive task. The above-mentioned power interactions apply in the first place to actors of equal dimension (such as organisations, participants), although they may also apply to combined dimensions. Often cited in this context is Etzioni's Compliance Theory, identifying three types of organisational power-coercive, utilitarian, and normative - that relate to three types of involvement-alienative, calculative, and moral—of the participants [133]. Most organisations show combinations of power 
types and involvement in three predictable combinations: coercive-alienative, utilitariancalculative, and normative-moral [133], that relate to the described power interactions as $(-,-),(-/ 0 /+)$, and $(+,+)$ respectively. The combination $(-/ 0 /+)$ shows any other interaction between the involvement of the participant and the organisational power strategy. Power shifts denote any significant change in power sharing. We consider power gaps as a result of the governance gaps discussed in (GovInst).

Evidence. (1) The 19th C sanitary revolution offers a striking example of power shifts between producers and consumers of drinking water, a tug-of-war having effects on societal organisation and governance institutions (see: [134]). (2) One of the main obstacles identified in an OECD policy survey is the lack of political will and leadership needed to shift the balance of power amongst stakeholders [14]. Inertia of institutions, resistance to change in power structure, and (perceived) costs related to transformation are considered important barriers to changing the water governance regime, in which prevail bureaucratic hierarchies and expert culture [32]. Pahl-Wostl [17] offers some explanation for this: participation of the civil society has become a major pillar in environmental resources management, which reduces the distinction between formal and informal institutions, but also blurs the roles of actors in more complex and intertwined governance regimes. (3) Rist et al. [103] notice that the more agents become interdependent, e.g., when dealing with resource management, the more they are likely to become subject to conflictive or competitive power-driven relationships emphasising differences. Biswas [98] wonders how the use, development, and management of natural resources-even if technically feasible - can be integrated, considering the intense inter- and intra-ministerial rivalries present in all countries. In his opinion, water professionals and ministries aiming for integrated water resources management have no say over land or agricultural resources, the level of integration being beyond their knowledge, expertise, and/or control. In terms of operability, the water management process-from the planning to the implementation and operational phase-is not inherently integrated. In contrast, Borowski-Maaser et al. [116] offer a good example of the way stakeholders involved gain benefits (also non-monetary, such as engagement) and power (e.g., by mandate). (4) Lepenies et al. [27] point out that variants of coproduction results in differences in decision-making power between experts, civil society, and elected decision-makers, which may obfuscate responsibilities and traceability of decisions between participants. Gupta and Pouw [6] indicate that relational inclusiveness is that part of 'inclusive development' that questions the underlying structural power politics that influence problem solving and calls for discursive politics focusing on the content. (5) An example of a power gap or shift is mentioned by Biswas [98], as some people use the popular concept of integrated water resources management to continue their usual practices under a fashionable label, aiming for greater acceptance and visibility, and to attract additional funds. In a more practical sense, Schulze and Schmeier [120] investigated the institutional capacity of river basin organisations (RBOs) to manage changes arising within their biophysical surrounding. They distinguish between implementation-oriented and coordination-oriented RBOs, which roughly corresponds with respectively a content-driven and managerial-driven governance style (PubGovStyl).

\subsection{Adaptive Cycle and Panarchy ( $\mathrm{AdCycl})$}

Concept. This unit is considered an 'archetype of systems dynamics' (see: [31]). The Adaptive Cycle shows the dynamics in cyclic and periodic processes of CASs, such as societal capitals and governance. It helps to understand why and how changes occur in similar ways in very different domains. The Panarchy concept shows interactions between different levels, be it spatial, organizational, or hierarchical. It helps to understand the scale-effect of changes.

Description. The Adaptive Cycle is meant to be a tool of thought [68], to understand the dynamics of (combinations of) ecological, economic, social, and governance processes. This general model of systemic change was first applied by Holling to ecological systems and by, inter alia, Gunderson et al. to human-ecological systems. The Adaptive Cycle and 
related Panarchy concept have been explained, discussed, and applied by a large number of researchers, very often for explaining ecosystem dynamics, but also socio-economic systems [22] and urban organisational structures [24]. The Adaptive Cycle describes the similarities in behaviour of complex adaptive systems (CAS) at different levels of organisation (Panarchy), including systemic properties such as-in the case of ecosystemsresilience, $\mathrm{r}-\mathrm{K}$ species selection, and equilibrium shifts $[21,22,24,68]$. It indicates that systems become vulnerable to either internal fluctuations or external disruptions in a particular phase of the cycle $[22,68,135]$. In this sense, vulnerability of ecosystems combines sensitivity and ecosystem value and is a measure of the degree ecosystems are susceptible to deterioration (SystHaz), (SystVal). The Adaptive Cycle explains the system's dynamics by four consecutive phases: rapid growth $(r)$, conservation $(K)$, release $(\Omega)$, and reorganisation $(\alpha)$ [68] and shows two strings: system development $(\alpha-\Omega)$ and creative destruction and reorganisation (r-K). For further reading on this subject: [21,22,24,68,136-138].

Within the ACCU approach, the Adaptive Cycle is helpful to explain synergies and interactions between a large number of units, triggered by (a combination of) shifting power interactions, institutional reform, increasing stakeholder participation and empowerment, a dynamic governance style, the development towards post-normal science, changing systems value, natural resources exploitation, systemic impacts, and systemic hazards.

Evidence. (1) Discussing governance aspects of the EU Water Framework Directive, Wuijts et al. [50] stress the importance of developing 'bridging mechanisms' to enhance connectivity between actors across hydrological scales, regional authorities, and institutional levels. (2) The importance of time and space scales of ES G\&Ss, applied to the Water Framework Directive/Elbe river basin, is explained by Bastian et al. [37], arguing, for instance, that ecological structures and processes, as well as ES G\&Ss, "manifest themselves at different scales and in quite different manners at the local, the regional and the global scale" [37] (p. 5).

\section{Application: The Pathology of Natural Resources Management}

Studying agricultural water management, Tortajada [139] concludes that in many basins worldwide the upper limits of water use (sustainability limits in (NatRes)), systemic limits in (SystVal)) have already been reached, now requiring transboundary water management with broader views (natural resources management in (DecMak)), including social and environmental concerns (CAPs), as well as policy levers outside the water sector (such as energy and food). In a few lines, Voinov et al. [140] describes the current situation as follows: (i) several planetary boundaries are being exceeded (systems potentials in (SystVal), damage in (SystHaz)), and (ii) social conflicts (social capital in (CAPs)) emerge due to decreasing resources or a shortage of water, energy, and land (depletion in (NatRes)), as a result of (iii) climate change, biodiversity loss, and affected ecosystem functioning (SystImp), although (iv) knowledge (KnowDom) and understanding of systems (DisKnow) increase, however (v) they do not automatically generate adequate policies or management strategies (DecMak). The conclusion is that (changes in) water management (PubGovStyl) cannot be achieved without integration of environmental, sectorial (SocOrg), and institutional/managerial ((GovInst), (OrgMgmt)) aspects. This kind of interaction is illustrated by the "pathology of natural resource management" of Holling and Meffe [21], although other kinds of interactions may play a role as well.

Water pollution and climate change (SystImp) are two well-known causes of decreasing water availability (depletion in (NatRes)) and the effects of this evolution have been studied by Holling and Meffe [21], developing their "pathology of natural resource management". It refers to the inability to enhance ecosystem resilience (resilience in (SystVal)) because responsible agencies perform immobilising instead of a flexible behaviour (conservative in (PubGovStyl)), incapable of fundamentally altering driving forces such as population growth. This pathology is initiated by a growing human population (pressures in (SystImp)) and results in a decrease of natural resources, which is responded to with an enforced top-down command and control by the agencies involved (conservative in (PubGovStyl)). 
The 'command-and-control' attitude of management agencies results in a contraction of the ecosystem resilience (resilience in (SystVal)) in cases of diminishing resources (depletion in (NatRes)) that are the negative effects of economic activities ((CAPs), (SystImp)). Continuous exploitation of natural resources results in increasing dependency on natural resources (RiskResp) and the ways it is controlled by our practices and responsible authorities (DecMak), whilst nature itself loses resilience (SystVal), increasing the likelihood unexpected events and ecosystem failures will occur ((SystHaz), (SystImp), (RiskResp)). This causes denial, forces the economy to meet their demands (CAPs), and pressures authorities for more command-and-control (PubGovStyl). After a while, management focuses merely on controlling efficiency, neglects basic responsibilities and initial objectives, and becomes rigid in structure ((OrgMgmt, DecMak)). Authorities will change internal policy by focusing on new goals (DecMak), shifting towards a reduction of research and monitoring (externalisation in (PubGovStyl)), to cost-efficiency, or even to an institutional survival strategy (DecMak). Institutions may become rigid and myopic because agency personnel become isolated from the systems to be managed, and because of the insensitivity to external (public) signals ((PubGovStyl, (SocOrg)). According to the authors, socio-economic institutions attempting to control ecosystems are confronted with erratic or surprising ecosystem behaviour (unpredictability in (SystImp)), which is responded to with more control ((DecMak), (OrgMgmt), (PubGovStyl)). Usually, this "results in unforeseen consequences for both natural ecosystems and human welfare in the form of collapsing resources, social and economic strife, and losses of biological diversity" (unexpected damage in (SystHaz)). Finally, an un-resilient bureaucracy (PubGovStyl) is established, insensitive to new challenges and discouraging innovation or other behavioural variance (innovation and leadership in (OrgMgmt), conservative in (PubGovStyl)).

In the example by Tortajada [139], agricultural water management limits the operationalisation of the concept of water governance (implementation in (OrgMgmt)) by focusing on the construction of new projects and no longer on the management of the resource ((DecMak), (CAPs), (NatRes)). The solution to this kind of aberrant form of management is not more regulations, but innovations (innovation in (OrgMgmt), (StructComp)) that finally result "in more resilient ecosystems, more flexible agencies, more self-reliant industries, and a more knowledgeable citizenry" (societal and institutional changes in (SystVal)). In this respect, this strongly relates to (PublGovStyl).

\section{Discussion}

The overall objective of the proposed concept is to develop a generally applicable tool for environmental analyses. It therefore aims to be holistic, integrative, diagnostic/analytical, visual, and dynamic. As such, the approach aims to combine theory and practice at a higher level of conceptualisation, allowing the identification of systemic elements and processes. The distinction between structural and contentual complexity is used as a means for arrangement of the units. Additionally, the question must be answered as to what extent this kind of concept contributes to gaining insights and supports governance.

The ACCU approach (Figure 3) details the Pentatope Model illustrated in Figure 1 and shows the points of interest (generalised in Figure 2) to be addressed when it comes to policy and management. In this way, it is holistic within the restraints of the research topic, allowing the identification of (other) areas of interest. Developing this approach revealed, however, that holism rather remains a perception with limited practical possibilities. It reminds us that research designs and systems analyses should aim for a broader perspective, but practice shows that deeper analysis is inherently reductionistic. The strength of ACCU is in exploring that broader perspective, but questions at the same time to what extent a practical application of the holism concept is feasible, knowing that any approach in that respect tends to result in an almost infinitely webbed structure of systemic properties and processes.

ACCU is integrative in describing complex environmental issues by aggregating mutually interacting units of interest. Selection and aggregation of units delineates both content, context, and extent of an issue. Interactions describe the dynamics within and 
between units. At first instance, the integration of contentual and structural units was envisaged, but during the process of development, it became clear that 'archetypes of systems dynamics' of natural, socio-economic, or socio-biological patterns-including the Adaptive Cycle, Panarchy, and Benefits/Power interactions-need to be included as a somewhat distinct group of units. Those archetypes are basically grounded in intrinsic system properties, such as seasonality and human behaviour. However, some properties, and in particular those that have a timescale dimension-e.g., process acceleration, path dependency, technological progress-reflect a dynamic nature and could not be included in the schema at this stage. It is expected that when dealing with other societal issues, the inclusion of additional archetypes may be required.

The ACCU approach should serve as a tool for analysis (identifying key elements) and diagnosis (identifying causes and effects). It shows the process dynamics within normal ranges, as well as the limits, levels, and areas when exceeding these ranges. At a higher level of conceptualisation (Figure 2), it is easy to distinguish between contentual and structural units, as well as the archetypes. However, at a more detailed level (Figure 3), features of content and structure seem to blur this. It hampers, for instance, a clear distinction between content-driven and managerial-driven governance styles. On the other hand, different types of 'uncertainty' —of crucial importance to decision-making and risk analysis—can be easily mapped on the ACCU schema, making it a valuable tool for analysis.

The ACCU approach is a means to visualise complexity. Instead of describing a multitude of interactions between process elements, the choice was to depict building blocks (units or elements) as piled containers, with the main features indicating the prevailing interactions between the units. The result then serves as a platform for common understanding, analysis, and discussion. Looking over the edges of separated units allows us to design a coherent approach with a uniformised terminology. It facilitates the mapping of ideas and thinking, a way to avoid, as Waylen et al. [107] indicate, the conflation of terminology and ideas that may also become problematic. However, visualisation has its limits. The more elements are included (either holistic or reductionistic), the more difficult it will be to get them properly presented in a single figure.

ACCU is dynamic in the way it helps to design and structure information from different sources and for different purposes. As such, this approach seems applicable to many different societal issues, including economic and social aspects (economic crises, cultural conflicts) or health crises (pandemics). The dynamic nature results from the fact that it is possible to select and arrange ACC-units according to the research needs. The number of units is not limited, their arrangement is not prescribed, and features can be chosen according to the issue concerned. For instance, (RiskResp), (SystImp), and (SystHaz) cover the Bowtie Method [141], a risk analysis method in which (DecMak), (CAPs), and (NatRes) can be included as well. Hence, the challenge is to select those items for discussion that are most prominent and obvious according to the nature of the issue, the available knowledge, and the actors' stakes. This approach is supported by Apitz [142] who argues that this kind of framework should only be as complex as needed, based on the context of the decision, and designed in a tiered and iterative manner to examine dominant processes, allowing one to apply details as it evolves. Extension with additional or replacement by alternative units is possible in different ways. With respect to (NatRes), further specification easily connects with the PT Model approach: resources availability with abiotic and biotic resources and ecosystem carrying capacity, habitat range, and resource use with demand and supply of commodities and economic processes, etc. (see: [20]). However, it can be assumed that in practice the number of workable aggregations is rather limited, given the mutual dependencies between unit properties.

Most of the characteristics described are combined in practice. At this moment, there is no reason to stick to a particular ACCU design, although there are arguments in favour of it. For instance, the ACCU presented in Figure 3 applies to issues dealing with environmental disturbances and related systemic impacts, but these units could be replaced by others when discussing social values (such as ethical issues) less or not subjected to 
harm, threats, or risks. This kind of flexible exercise visualises and binds the area of interest according to a personal aggregation of units, the process of analysis providing insight into the issue. A potential drawback is the generation of an array of different visualisations on the same issue. In this respect, the use of the same conceptual platform could benefit comparability between users and their products, applying to some extent the same vocabulary, definitions, descriptions, and tools. Apitz [142] calls for the development of a common, cross-sectoral vocabulary that allows for communication or even integration across frameworks, management sectors, and between science and applications.

Finally, this concept demands some reflection on the extent to which it may contribute to not only understanding but also resolving thematic issues. In this respect, ACCU becomes a policy and management supporting tool. A similar thought about the added value of ACCU can be formulated as Waylen et al. [107] do for the Ecosystem Approach, questioning if it is contributing to highlighting the complexity of socio-ecological systems only, or if it will be also of use in resolving management challenges associated with this complexity. This means that navigating through this complex of units and interactions should allow us to draw main conclusions from a holistic perspective, as well as specific conclusions from a particular analysis, which is water governance in this case. Experiences with ACCU show that the analysis of the combined contentual/structural complexity of an issue results in a description of braided interactions within and between units. Referring to societal transitions towards sustainability, the ACCU approach enlarges the 'responses' of DPSIR towards governance, and beyond, towards systemic and behavioural change. In short, ACCU forces us to at least consider all aspects of DPSIR, drivers and responses included. The following finding illustrates the added value of ACCU by feeding the discussion at a more detailed level. It deals with the fact that boundaries of complexity are marked by areas of uncertainty. According to van Bueren et al. [33], uncertainty can be of cognitive, strategic, or institutional nature, of which the last two emerge from intensified actor participation. However, they also argue that decisions can only be handled adequately by enhancing and intensifying stakeholder interactions. This seems to be a crucial statement when dealing with complex issues, as it leaves no other possibility than to exchange information and knowledge, discuss in open arenas, and convince actors to change behaviour. The time this requires is likely to conflict with the urgency of solving complex issues by applying measures to reduce uncertainty. Uncertainty reduction depends on the extent of the contribution of substantive decisions (ranging from non-decisions to innovative decisions), changed strategies, and institutional effects [33]. This potential conflict emerges from the ACCU approach.

\section{Conclusions}

The ACCU approach aims to be holistic, integrative, diagnostic/analytical, visual, and dynamic and could therefore serve as a guidance and analytical tool for societal processes, and in particular complex environmental issues. It is shown that it is possible to design a framework of components of complex adapted systems and basic concepts of process functioning that relate to (water) governance, structured according to their most plausible interactions. This framework allows us to address structural and contentual complexity in a combined way, providing insight into thematic issues, but also holding the potential to support policy and management.

Author Contributions: Conceptualization, R.V. and P.L.M.G.; methodology, R.V.; writing—original draft preparation, R.V.; writing — review and editing, P.L.M.G.; supervision, P.L.M.G. All authors have read and agreed to the published version of the manuscript.

Funding: This research received no external funding.

Institutional Review Board Statement: Not applicable.

Informed Consent Statement: Not applicable.

Data Availability Statement: Not applicable. 
Acknowledgments: The authors are very grateful to the anonymous reviewers of this paper for their valuable comments.

Conflicts of Interest: The authors declare no conflict of interest.

\section{Acronyms and Abbreviations}

\begin{tabular}{|c|c|}
\hline ACCU/ACC-unit & Aggregation of Concepts and Complex Adapted Systems Units \\
\hline AdCycl & Adaptive Cycle \\
\hline BAU & business-as-usual \\
\hline BenPowInta & benefits/power interactions \\
\hline CAC & Command-and-Control \\
\hline CAPs & societal capitals \\
\hline CAS & Complex Adaptive System \\
\hline CC & carrying capacity \\
\hline CIM & Central and Intermediate Modules \\
\hline ContComp & contentual complexity \\
\hline DecMak & decision-making \\
\hline DiscKnow & disciplinary knowledge \\
\hline DPSIR & Disturbance chain (Drivers-Pressures-Status-Impacts-Responses) \\
\hline E & effect \\
\hline EIA & Environmental Impact Assessment \\
\hline EIC & environmental information cycle \\
\hline ES CC & ecosystem carrying capacity \\
\hline ES G\&Ss & ecosystem goods and services \\
\hline ES & ecosystem \\
\hline EU & European Union \\
\hline Fs\&Us & functions and uses \\
\hline GASI & governance by actor-subject impact analysis \\
\hline $\mathrm{HR}$ & habitat range \\
\hline IWRM & integrated water resources management \\
\hline KnowDom & knowledge domains \\
\hline NatRes & natural resources (as ACC-unit) \\
\hline NBS & nature-based solutions \\
\hline NR (mgmt) & natural resources (as ecosystem good and service) (management) \\
\hline OrgMgmt & organisational management \\
\hline PNS & Post-Normal Science \\
\hline ProbSolvStrat & problem-solving strategies \\
\hline PTM, PT Model & Pentatope Model \\
\hline PubGovStyl & public governance styles \\
\hline RiskResp & risks and responses \\
\hline SD & system dynamics \\
\hline SEA & Strategic Environmental Assessment \\
\hline SocOrg & governance institutions \\
\hline SocOrg & societal organisation \\
\hline StructComp & structural complexity \\
\hline SystHaz & systemic hazard \\
\hline SystImp & systemic impacts \\
\hline SystVal & systems value \\
\hline $\mathrm{T}$ & time $(\Delta \mathrm{T}$ : time period $)$ \\
\hline Water Framework Directive WFD & EU Water Framework Directive \\
\hline
\end{tabular}

\section{References}

1. OECD. Water Governance in OECD Countries-A Multi-Level Approach; OECD Studies on Water; OECD Publishing: Paris, France, 2011; 241p. [CrossRef]

2. Palmer, C.G.; Biggs, R.; Cumming, G.S. Applied research for enhancing human well-being and environmental stewardship: Using complexity thinking in Southern Africa. Ecol. Soc. 2015, 20, 53. [CrossRef] 
3. Gómez-Baggethun, E.; de Groot, R.; Lomas, P.L.; Montes, C. The history of ecosystem services in economic theory and practice: From early notions to markets and payment schemes. Ecol. Econ. 2010, 69, 1209-1218. [CrossRef]

4. Gómez-Baggethun, E.; Ruiz-Pérez, M. Economic valuation and the commodification of ecosystem services. Prog. Phys. Geogr. 2011, 35, 613-628. [CrossRef]

5. UN EMG. Working Towards a Balanced and Inclusive Green Economy: A United Nations System-wide Perspective; Prepared by the Environment Management Group; United Nations: Geneva, Switzerland, 2011; 201p.

6. Gupta, J.; Pouw, N. Towards a trans-disciplinary conceptualization of inclusive development. Curr. Opin. Environ. Sustain. 2017, 2017, 1-8. (In Press) [CrossRef]

7. Vannevel, R. Using DPSIR and Balances to Support Water Governance. Water 2018, 10, 118. [CrossRef]

8. OECD. Water Resources Allocation: Sharing Risks and Opportunities; OECD Studies on Water; OECD Publishing: Paris, France, 2015; 141p, Available online: https: / / read.oecd-ilibrary.org/environment/water-resources-alloction_9789264229631-en\#page3 (accessed on 23 June 2021). [CrossRef]

9. Vannevel, R. Learning from the past: Future water governance using historic evidence of urban pollution and sanitation. Sustain. Water Qual. Ecol. 2017, 9-10, 27-38. [CrossRef]

10. Madani, K.; Shafiee-Jood, M. Socio-hydrology: A new understanding to unite or a new science to divide? Water 2020, $12,1941$. [CrossRef]

11. EC. Directive 2000/60/EC of the European Parliament and of the Council of 23 October 2000 Establishing a Framework for Comunity Action in the Field of Water Policy. OJ L 327, 22.12.2000. 2000, pp. 1-73. Available online: https:/ / eur-lex.europa.eu/ legal-content/EN/TXT/PDF/?uri=CELEX:32000L0060\&from=EN (accessed on 23 June 2021).

12. Carvalho, L.; Mackay, E.B.; Cardoso, A.C.; Baattrup-Pedersen, A.; Birk, S.; Blackstock, K.L.; Borics, G.; Borja, A.; Feld, C.K.; Ferreira, M.T.; et al. Protecting and restoring Europe's waters: An analysis of the future development needs of the Water Framework Directive. Sci. Total Environ. 2019, 658, 1228-1238. [CrossRef]

13. Akhmouch, A.; Correia, F.N. The 12 OECD principles on water governance-When science meets policy. Util. Policy 2016, 43, 14-20. [CrossRef]

14. Akhmouch, A.; Clavreul, D. Stakeholder engagement for inclusive water governance: "Practicing What We Preach" with the OECD water governance initiative. Water 2016, 8, 204. [CrossRef]

15. Romano, O.; Akhmouch, A. Water governance in cities: Current trends and future challenges. Water 2019, 11, 500. [CrossRef]

16. Corbett, T.; Dimas, J.; Fong, J.; Noyes, J.L. The challenge of institutional "milieu" to cross-systems integration. Focus 2005, 24, 28-35.

17. Pahl-Wostl, C. A conceptual framework for analysing adaptive capacity and multi-level learning processes in resource governance regimes. Glob. Environ. Chang. 2009, 19, 354-365. [CrossRef]

18. Vannevel, R. The Pentatope Model: A holistic approach for analysing and reviewing environmental complexity. Sustain. Water Qual. Ecol. 2013, 1-2, 10-23. [CrossRef]

19. Vannevel, R. Consequences of Increasing Environmental Complexity in the Water Domain. Water Resour. Dev. 2011, 27, 639-653. [CrossRef]

20. Vannevel, R.; Goethals, P.L.M. Identifying Ecosystem Key Factors to Support Sustainable Water Management. Sustainability 2020, 12, 1148. [CrossRef]

21. Holling, C.S.; Meffe, G.K. Command and control and the pathology of natural resource management. Conserv. Biol. 1996, 10, 328-337. [CrossRef]

22. Gunderson, L.H. Comparing Ecological and Human Community Resilience; CARRI Research Report; Community and Regional Resilience Initiative, Oak Ridge National Laboratory, Emory University, Atlanta, GA, USA. 5 January 2009. 17p. Available online: http:/ / www.resilientus.org/wp-content/uploads/2013/03/Final_Gunderson_1-12-09_1231774754.pdf (accessed on 21 June 2021).

23. Berkes, F. Environmental governance for the anthropocene? Social-ecological systems, resilience, and collaborative learning. Sustainability 2017, 9, 1232. [CrossRef]

24. Folke, C. Resilience: The emergence of a perspective for social-ecological systems analyses. Glob. Environ. Chang. 2006, 16, 253-267. [CrossRef]

25. Funtowicz, S.O.; Ravetz, J.R. Uncertainty, complexity and post-normal science. Environ. Toxicol. Chem. 1994, 13, 1881-1885. [CrossRef]

26. Lautenbach, S.; Mupepele, A.-C.; Dormann, C.F.; Lee, H.; Schmidt, S.; Scholte, S.S.K.; Seppelt, R.; van Teeffelen, A.J.A.; Verhagen, W.; Volk, M. Blind spots in ecosystem services research and challenges for implementation. Reg. Environ. Chang. 2019, 19, 2151-2172. [CrossRef]

27. Lepenies, R.; Hüesker, F.; Beck, S.; Brugnach, M. Discovering the Political implications of coproduction in water governance. Water 2018, 10, 1475. [CrossRef]

28. Levin, K.; Cashore, B.; Bernstein, S.; Auld, G. Playing it forward: Path dependency, progressive incrementalism, and the "super wicked" problem of global climate change. In Proceedings of the International Studies Association Convention, Chicago, IL, USA, 28 February-3 March 2007; Version June 3, 2010. Available online: http:/ / citeseerx.ist.psu.edu/viewdoc/download?doi=10.1.1.4 64.5287\&rep=rep1\&type=pdf (accessed on 4 June 2020).

29. Maani, K. Decision-Making for Climate Change Adaptation: A Systems Thinking Approach; National Climate Change Adaptation Research Facility: Gold Coast, Australia, 2013; 67p, Available online: https:/ / core.ac.uk/download/pdf/30676626.pdf (accessed on 23 June 2021). 
30. Máñez, M.; Carmona, C.; Gerkensmeier, B. Assessing Governance Performance; Report 20; Climate Service Centre Germany: Hamburg, Germany, 2014; 45p.

31. Morgan, P. The Idea and Practice of Systems Thinking and Their Relevance for Capacity Development; European Centre for Development Policy Management: Maastricht, The Netherlands, 2005; 33p, Available online: https:/ / ecdpm.org/wp-content/uploads/2005 -Idea-Practice-Systems-Thinking-Relevance-Capacity-Development.pdf (accessed on 23 June 2021).

32. Pahl-Wostl, C. The implications of complexity for integrated resources management. Environ. Model. Softw. 2007, 22, 561-569. [CrossRef]

33. van Bueren, E.M.; Klijn, E.H.; Koppenjan, J.F.M. Dealing with wicked problems in networks: Analyzing an environmental debate from a network perspective. J. Public Adm. Res. Theory 2003, 13, 193-212. [CrossRef]

34. Holling, C.S. Resilience and stability of ecological systems. Annu. Rev. Ecol. Syst. 1973, 4, 1-23. [CrossRef]

35. van de Meene, S.J.; Brown, R.R.; Farrelly, M.A. Towards understanding governance for sustainable urban water management. Glob. Environ. Chang. 2011, 21, 1117-1127. [CrossRef]

36. Buchanan, R. Wicked Problems in Design Thinking. Des. Issues 1992, 8, 5-21. [CrossRef]

37. Bastian, O.; Grunewald, K.; Syrbe, R.-U. Space and time aspects of ecosystem services, using the example of the EU Water Framework Directive. Int. J. Biodivers. Sci. Ecosyst. Serv. Manag. 2012, 5-16. [CrossRef]

38. Boik, J.C. Science-driven societal transformation, Part I: Worldview. Sustainability 2020, 12, 6881. [CrossRef]

39. Raskin, P.; Chadwick, M.; Jackson, T.; Leach, G. The Sustainability Transition: Beyond Conventional Development; Stockholm Environment Institute: Stockholm, Sweden, 1996; 91p.

40. Atkins, J.P.; Burdon, D.; Elliott, M.; Gregory, A.J. Management of the marine environment: Integrating ecosystem services and societal benefits with the DPSIR framework in a systems approach. Mar. Pollut. Bull. 2011, 62, 215-226. [CrossRef]

41. Grosskurth, J.; Rotmans, J. The scene model: Getting a grip on sustainable development in policy making. Environ. Dev. Sustain. 2005, 7, 135-151. [CrossRef]

42. O'Connor, M. The "Four Spheres" framework for sustainability. Ecol. Complex. 2006, 3, 285-292. [CrossRef]

43. Ekins, P.; Dresner, S.; Dahlström, K. The Four-Capital Method of Sustainable Development Evaluation. Eur. Env. 2008, 18, 63-80. [CrossRef]

44. Munasinghe, M. Integrated solutions for water, sustainable development and climate change issues: Applying the sustainomics framework. In On the Water Front.-Selections from the 2009 World Water Week in Stockholm; Lundqvist, J., Ed.; Stockholm International Water Institute (SIWI): Stockholm, Sweden, 2009; pp. 46-55.

45. Nardini, A.G.C.; Conte, G. River management \& restoration: What river do we wish for. Water 2021, 13, 1336. [CrossRef]

46. Mirzaei, A.; Saghafian, B.; Mirchi, A.; Madani, K. The groundwater-energy-food nexus in Iran's agricultural sector: Implications for water security. Water 2019, 11, 1835. [CrossRef]

47. Eriyagama, N.; Smakhtin, V.; Udamulla, L. Sustainable surface water storage development pathways and acceptable limits for river basins. Water 2021, 13, 645. [CrossRef]

48. England, R.W. Natural capital and the theory of economic growth. Ecol. Econ. 2000, 34, 425-431. [CrossRef]

49. Baron, J.S.; Poff, N.L.; Angermeier, P.L.; Dahm, C.L.; Gleick, P.H.; Hairston, N.G.; Jackson, R.B.; Johnston, C.A.; Richter, B.D.; Steinman, A.D. Meeting ecological and societal needs for freshwater. Ecol. Appl. 2002, 12, 1247-1260. [CrossRef]

50. Wuijts, S.; Van Rijswick, H.F.M.W.; Driessen, P.P.J. Achieving European Water Quality Ambitions: Governance Conditions for More Effective Approaches at the Local-Regional Scale. Sustainability 2021, 13, 681. [CrossRef]

51. Ponnambalam, K.; Mousavi, S.J. CHNS modeling for study and management of human-Water interactions at multiple scales. Water 2020, 12, 1699. [CrossRef]

52. OECD. Environmental Outlook and Strategy_Biodiversity; ENV/EPOC/GEEI/BIO(2001)2/FINAL; Working Party on economic and Environmental Policy Integration-Working Party on Economic Aspects of Biodiversity, 13 March 2001; OECD: Paris, France, $2001 ; 33 p$.

53. Eurostat. Key Indicators for Sustainable Development; Paper Presented by Eurostat. Joint ECE/Eurostat Work Session on Methodological Issues of Environmental Statistics (Ottawa, 1-4.10.2001); Working Paper No. 26; Eurostat: Luxembourg, 2001.

54. Smith, C.; Papadopoulou, N.; Barnard, S.; Mazik, K.; Patrício, J.; Elliott, M.; Solaun, O.; Little, S.; Borja, A.; Bhatia, N.; et al. Conceptual Models for the Effects of Marine Pressures on Biodiversity. Hellinic Centre for Marine Research. DEVOTESDevelopment of Innovative Tools for Understanding Marine Biodiversity and Assessing Good Environmental Status. Deliverable 1.1. 23 June 2014. 82 p. Available online: http://www.devotes-project.eu/wp-content/uploads/2014/06/DEVOTES-D1-1 -ConceptualModels.pdf (accessed on 21 June 2021).

55. Kurtz, C.F.; Snowden, D.J. The new dynamics of strategy: Sense-making in a complex and complicated world. IBM Syst. J. 2003, 42, 462-483. [CrossRef]

56. Cynefin Concept. Available online: https://en.wikipedia.org/wiki/Cynefin_framework (accessed on 21 January 2021).

57. Boik, J.C. Science-driven societal transformation, Part II: Motivation and strategy. Sustainability 2020, 12, 8047. [CrossRef]

58. Walker, W.E.; Harremöes, P.; Rotmans, J.; Van Der Sluijs, J.P.; Van Asselt, M.B.A.; Janssen, P.; Krayer Von Krauss, M.P. Defining Uncertainty-A Conceptual Basis for Uncertainty Management in Model-Based Decision Support. Integr. Assess. 2003, 4, 5-17. [CrossRef]

59. Landuyt, D.; Broeckx, S.; Engelen, G.; Uljee, I.; Van der Meulen, M.; Goethals, P.L.M. The importance of uncertainties in scenario analyses-A study on future ecosystem service delivery in Flanders. Sci. Total Environ. 2016, 553, 504-518. [CrossRef] 
60. EEA. European Environment - State and Outlook 2015: Assessment of Global Megatrends; European Environment Agency: Copenhagen, Denmark, 2015; 134p. [CrossRef]

61. OECD. OECD Environmental Outlook to 2050; OECD Publishing: Paris, France, 2012; 353p. [CrossRef]

62. UNEP. Measuring Water Use in a Green Economy; A report of the Working Group on Water Efficiency to the International Resource Panel; United Nations Environment Programme, UNEP: Nairobi, Kenya, 2012; 72p.

63. Hazard. Available online: https:/ / www.dmp.wa.gov.au/Safety/What-is-a-hazard-and-what-is-4721.aspx (accessed on 15 March 2021).

64. Farrar, C.R.; Sohn, H.; Park, G. Converting large sensor array data into structural health information. In The 4th International Workshop on Structural Control; Smyth, A., Betti, R., Eds.; Columbia University: New York City, NY, USA, 2004.

65. UNDRR—Risk. Available online: https://www.unisdr.org/we/inform/terminology (accessed on 15 March 2021).

66. WRI. Aqueduct 3.0: Updated Decision-Relevant Global Water Risk Indicators; Technical Note, July 2019; World Resources Institute: Washington, DC, USA, 2019; 53p.

67. EC. Directive 2004/35/CE of the European Parliament and of the Council of 21 April 2004 on Environmental Liability with Regard to the Prevention and Remedying of Environmental Damage. European Commission, Official Journal, L 143, 30/04/2004. 2004, pp. 56-75. Available online: https:// eur-lex.europa.eu/legal-content/EN/TXT/?uri=celex\%3A32004L0035 (accessed on 23 June 2021).

68. Peterson, G. Political ecology and ecological resilience: An integration of human and ecological dynamics. Ecol. Econ. 2000, 35, 323-336. [CrossRef]

69. de Boer, T.; Paltan, H.; Sternberg, T.; Wheeler, K. Evaluating vulnerability of Central Asian water resources under uncertain climate and development conditions: The case of the Ili-Balkhash basin. Water 2021, 13, 615. [CrossRef]

70. Naeem, B.; Azmat, M.; Tao, H.; Ahmad, S.; Khattak, M.U.; Haider, S.; Ahmad, S.; Khero, Z.; Goodell, C.R. Flood hazard assessment for the tori levee breach of the indus river basin, Pakistan. Water 2021, 13, 604. [CrossRef]

71. van Klink, R.; Bowler, D.E.; Gongalsky, K.B.; Swengel, A.B.; Gentile, A.; Chase, J.M. Meta-analysis reveals declines in terrestrial but increases in freshwater insect abundances. Science 2020, 368, 417-420. [CrossRef] [PubMed]

72. EC. General Union Environment Action Programme to 2020; Living Well, within the Limits of Our Planet; European Commission, Publication Office of the European Union: Luxembourg, 2014; 87p. [CrossRef]

73. Parrish, J.D.; Braun, D.P.; Unnasch, R.S. Are we conserving what we say we are? Measuring ecological integrity within protected areas. BioScience 2003, 53, 851-860. [CrossRef]

74. Gunderson, L.H. Ecological resilience-In theory and application. Annu. Rev. Ecol. Syst. 2000, 2000, 425-439. [CrossRef]

75. EU Council. The Fitness Check of EU Freshwater policy. In Commission Staff Working Document; SWD(2012) 393 final; Council of the European Union: Brussels, Belgium, 20 November 2012; 47p.

76. EEA. European Waters-Current Status and Future Challenges. Synthesis; EEA Report N 9/2012; European Environment Agency: Copenhagen, Denmark, 2012; 52p.

77. Poff, N.L. Landscape filters and species traits: Towards mechanistic understanding and prediction in stream ecology. J. N. Am. Benthol. Society 1997, 16, 391-409. [CrossRef]

78. EEA. EEA Programming Document 2017-2019_Expanding the Knowledge Base for Policy Implementation and Long-Term Transitions; Adopted by the EEA Management Board on 7 December 2016; European Environment Agency: Copenhagen, Denmark, 2016; 144p, Available online: https: / www.eea.europa.eu/publications/programming-document-2017-2019 (accessed on 23 June 2021).

79. Zins, C. Conceptual Approaches for Defining Data, Information, and Knowledge. J. Am. Soc. Inf. Sci. Technol. 2007, 58, 479-493. [CrossRef]

80. ECC. Council Directive 85/337/EEC of 27 June 1985 on the Assessment of the Effects of Certain Public and Private Projects on the Environment; Official Journal L 175, 05/07/1985; European Union: Brussels, Belgium, 1985; pp. 40-48.

81. EC. Directive 2001/42/EC of the European Parliament and of the Council of 27 June 2001 on the Assessment of the Effects of Certain Plans and Programmes on the Environment. European Commission. Official Journal of the European Communities, L 197/30. 2001. Available online: https:/ / eur-lex.europa.eu/legal-content/EN/TXT/PDF/?uri=CELEX:32001L0042\&from=EN (accessed on 20 June 2021).

82. Rittel, H.W.J.; Webber, M.M. Planning problems are wicked problems. In Developments in Design Methodology; Cross, N., Ed.; John Wiley \& Sons: Hoboken, NJ, USA, 1984; pp. 135-144.

83. Feio, M.J.; Hughes, R.M.; Callisto, M.; Nichols, S.J.; Odume, O.N.; Quintella, B.R.; Kuemmerlen, M.; Aguiar, F.C.; Almeida, S.F.P.; Alonso-EguíaLis, P.; et al. The biological assessment and rehabilitation of the world's rivers: An overview. Water 2021, 13, 371. [CrossRef]

84. Rowley, J. The wisdom hierarchy: Representations of the DIKW hierarchy. J. Inf. Commun. Sci. 2007, 33, 163-180. [CrossRef]

85. DIKW. Available online: https://en.wikipedia.org/wiki/DIKW_pyramid (accessed on 18 August 2020).

86. Tolk, A. An agent-based decision support system architecture for the military domain. Intell. Decis. Support Syst. Agent-Mediat. Environ. 2005, 115, 187-205. Available online: https: / / www.researchgate.net/publication/242786163 (accessed on 23 June 2021).

87. Zhou, X.; Wang, F.; Huang, K.; Zhang, H.; Yu, J.; Han, A.Y. System Dynamics-Multiple Objective Optimization Model for Water Resource Management: A Case Study in Jiaxing City, China. Water 2021, 13, 671. [CrossRef]

88. Madigan, M.L. Handbook of Emergency Management Concepts: A Step-by-Step Approach; CRC Press: Boca Raton, FL, USA, 2017; 359p, Available online: https:/ / books.google.be/books?id=MtRBDwAAQBAJ\&dq=The+probability+or+threat+of+quantifiable+damage, 
+injury, +liability,+loss, +or+any+other+negative+occurrence+that+is+caused+by+external+or+internal+vulnerabilities, +and+that+ may+be+avoided+through+preemptive+action\&hl=nl\&source=gbs_navlinks_s (accessed on 23 June 2021).

89. Oral, H.V.; Carvalho, P.; Gajewska, M.; Ursino, N.; Masi, F.; van Hullebusch, E.D.; Kazak, J.K.; Exposito, A.; Cipolletta, G.; Andersen, T.R.; et al. A review of nature-based solutions for urban water management in European circular cities: A critical assessment based on case studies and literature. Blue-Green Syst. 2020, 1, 112-136. [CrossRef]

90. Voulvoulis, N.; Dominicarpon, K.; Giakoumis, T. The EU Water Framework Directive: From Great Expectations to Problems With Implementation. Sci. Total Environ. 2017, 575, 358-366. [CrossRef] [PubMed]

91. Wuijts, S.; Driessen, P.P.J.; Van Rijswick, H.F.M.W. Towards More Effective Water Quality Governance: A Review of SocialEconomic, Legal and Ecological Perspectives and Their Interactions. Sustainability 2018, 10, 914. [CrossRef]

92. Connick, S.; Innes, J.E. Outcomes of Collaborative Water Policy Making: Applying Complexity Thinking to Evaluation. J. Environ. Plan. Manag. 2003, 46, 177-197. [CrossRef]

93. Plummer, R.; Armitage, D. A resilience-based framework for evaluating adaptive co-management: Linking ecology, economics and society in a complex world. Ecol. Econ. 2007, 61, 62-74. [CrossRef]

94. Torres, C.J.F.; Peixoto de Lima, C.H.; de Almeida Goodwin, B.S.; de Aguiar Junior, T.R.; Fontes, A.S.; Ribeiro, D.V.; da Silva, R.S.X.; Pinto Medeiros, Y.D. Literature review to propose a systematic procedure to develop "Nexus Thinking" considering the water-energy-food nexus. Sustainability 2019, 11, 7205. [CrossRef]

95. Phan, T.C.; Smart, J.C.R.; Stewart-Koster, B.; Sahin, O.; Hadwen, W.L.; Dinh, L.T.; Tahmasbian, I.; Capon, S.J. Applications of bayesian networks as decision support tools for water resource management under climate change and socio-economic stressors: A critical appraisal. Water 2019, 11, 2642. [CrossRef]

96. Branches of Science. Available online: https:/ / en.wikipedia.org/wiki/Branches_of_science (accessed on 25 May 2021).

97. Kaiser, F.G.; Fuhrer, U. Ecological behavior's dependency on different forms of knowledge. Appl. Psychol. 2003, 52, 598-613. [CrossRef]

98. Biswas, A.K. Integrated water resources management: A reassessment. A water forum contribution. Water Int. 2004, 29, 248-256. [CrossRef]

99. Larson, K.L.; Redman, E.N. Water education for sustainability: Criteria and recommendations. Soc. Nat. Resour. 2014, 27, 1213-1222. [CrossRef]

100. Schneiderhan-Opel, J.; Bogner, F.X. The effect of environmental values on German primary school students' knowledge on water supply. Water 2021, 13, 702. [CrossRef]

101. LaDue, N.D.; Ackerman, J.R.; Blaum, D.; Shipley, T.F. Assessing water literacy: Undergraduate student conceptions of groundwater and surface water flow. Water 2021, 13, 622. [CrossRef]

102. Brugnach, M.; Özerol, G. Knowledge Co-Production and Transdisciplinarity: Opening Pandora's Box. Water 2019, $11,1997$. [CrossRef]

103. Rist, S.; Chidambaranathan, M.; Escobar, C.; Wiesmann, U.; Zimmermann, A. Moving from sustainable management to sustainable governance of natural resources: The role of social learning processes in rural India, Bolivia and Mali. J. Rural. Stud. 2007, 23, 23-37. [CrossRef]

104. Braat, L. The predictive meaning of sustainability indicators. In Search of Indicators of Sustainable Development, 1st ed.; Kuik, O., Verbruggen, H., Eds.; Environment \& Management-Kluwer Academic Publishers/Springer Science+Business Media: Dordrecht, The Netherlands, 1991; Volume 1, pp. 57-70.

105. ECDC. Towards One Health Preparedness; European Centre for Disease Prevention and Control: Stockholm, Sweden, 2018; 16p. [CrossRef]

106. Ceola, S.; Montanari, A.; Krueger, T.; Dyer, F.J.; Kreibich, H.; Westerberg, I.; Carr, G.; Cudennec, C.; Elshorbagy, A.; Savenije, H.; et al. Adaptation of water resources systems to changing society and environment: A statement by the International Association of Hydrological Sciences. Hydrol. Sci. J. 2016, 61, 2803-2817. [CrossRef]

107. Waylen, K.A.; Hastings, E.J.; Banks, E.A.; Holstead, K.L.; Irvine, R.J.; Blackstock, K.L. The Need to Disentangle Key Concepts from Ecosystem-Approach Jargon. Conserv. Biol. 2014, 28, 1215-1224. [CrossRef] [PubMed]

108. Martín-López, B.; Gómez-Baggethun, E.; García-Llorentea, M.; Montes, C. Trade-offs across value-domains in ecosystem services assessment. Ecol. Indic. 2014, 37, 220-228. [CrossRef]

109. Rutten, G.; Cinderby, S.; Barron, J. Understanding complexity in freshwater management: Practitioners' perspectives in The Netherlands. Water 2020, 12, 593. [CrossRef]

110. Hersey, P.; Blanchard, K.H.; Johnson, D.E. Management of Organizational Behaviour: Utilizing Human Resources, 7th ed.; Prentice Hall, Inc.: Upper Saddle River, NJ, USA, 1996; 627p.

111. Capacity. Available online: https://www.undrr.org/terminology/capacity (accessed on 8 May 2021).

112. Howsam, P.; Leeds-Harrison, P.; Weatherhead, K. Water Policy in Practice; Water \& Environment International: Redhill, UK, $1999 ;$ pp. 34-35.

113. Iribarnegaray, M.A.; Seghezzo, L. Governance, sustainability and decision making in water and sanitation management systems. Sustainability 2012, 4, 2922-2945. [CrossRef]

114. Driessen, P.P.J.; Dieperink, C.; van Laerhoven, F.; Runhaar, H.A.C.; Vermeulen, W. Towards a conceptual framework for the study of shifts in modes of environmental governance-Experiences from The Netherlands. Environ. Policy Gov. 2012, 22, 143-160. [CrossRef] 
115. Hajer, M.A.; van Tatenhove, J.P.M.; Laurent, C. Nieuwe Vormen van Governance. Onderzoeksteam Perform/ASSR, Universiteit van Amsterdam, in Opdracht van het MNP-RIVM; RIVM rapport 500013004/2004; RIVM: Bilthoven, The Netherlands, 2004; 37p.

116. Borowski-Maaser, I.; Graversgaard, M.; Foster, N.; Prutzer, M.; Roest, A.; Boogaard, F. WaterCoG: Evidence on How the Use of Tools, Knowledge, and Process Design Can Improve Water Co-Governance. Water 2021, 13, 1206. [CrossRef]

117. OECD. The Governance of Regulators. OECD Best Practice Principles for Regulatory Policy; OECD Publishing: Paris, France, 2014; 119p. [CrossRef]

118. Gregory, A.J.; Atkins, J.P.; Burdon, D.; Elliott, M. A problem structuring method for ecosystem-based management: The DPSIR modelling process. Eur. J. Oper. Res. 2013, 227, 558-569. [CrossRef]

119. Bandaragoda, D.J.; Babel, M.S. Institutional development for IWRM: An international perspective. Int. J. River Basin Manag. 2010, 8, 215-224. [CrossRef]

120. Schulze, S.; Schmeier, S. Governing environmental change in international river basins: The role of river basin organizations. Int. J. River Basin Manag. 2012, 10, 229-244. [CrossRef]

121. IMWI. The Challenges of Integrated River Basin Management in India; IWMI Water Policy Briefing 003; International Water Management Institute, IWMI-TATA Water Policy Program, IMWI: Colombo, Sri Lanka, 2002; 6p. [CrossRef]

122. EEA. Sustainability Transitions: Now for the Long Term; Eionet report No 1/2016; European Environment Agency: Copenhagen, Denmark, 2016; 86p. [CrossRef]

123. Barty-King, H. Water: The Book. An Illustrated History of Water Supply and Wastewater in the United Kingdom; Quiller Press: London, UK, 1992; 256p.

124. OECD. OECD Principles on Water Governance; OECD Publishing: Paris, France, 2015; 22p, Available online: http://www.oecd. org/governance/oecd-principleson-water-governance.htm (accessed on 23 June 2021).

125. Schwartz, S.H. An overview of the schwartz theory of basic values. Online Read. Psychol. Cult. 2012, 2, 1-20. [CrossRef]

126. van Dokkum, R.; Stortelder, P.B.M.; Leonard, J.; Brusske, A.; Falcke, H.; Rayneau, J.P. Estimation methods of industrial waste water pollution in the Meuse River Basin. Eur. Water Manag. 1999, 2, 51-61.

127. Reed, B. Shifting from 'sustainability' to regeneration. Build. Res. Inf. 2007, 35, 674-680. [CrossRef]

128. Bellamy, J.A.; Walker, D.H.; McDonald, G.T.; Syme, G.J. A systems approach to the evaluation of natural resource management initiatives. J. Environ. Manag. 2001, 63, 407-423. [CrossRef] [PubMed]

129. Commons Transition. Available online: http:/ / commonstransition.org/about-commons-transition-2/ (accessed on 8 June 2021).

130. Ricklefs, R.E. The Economy of Nature. A Textbook in Basic Ecology, 4th ed.; W.H. Freeman and Company: New York City, NY, USA, 1997; 678p.

131. Stiling, P. Ecology. Theories and Applications, 2nd ed.; Prentice Hall: Hoboken, NJ, USA, 1996; 539p.

132. Holmes, S. Henderson's Dictionary of Biological Terms, 9th ed.; Longman: London, UK; New York, NY, USA, 1979; 510p.

133. Lunenberg, F.C. Compliance theory and organizational effectiveness. IJSAID 2012, 14, 1-4.

134. Trentmann, F; Taylor, V. From users to consumers: Water politics in nineteenth century London. In The Making of the Consumer: Knowledge, Power and Identity in the Modern World; Trentmann, F., Ed.; Berg Publishers: Oxford, UK, 2005; pp. 53-79.

135. Ge, L.; Anten, N.P.R.; van Dixhoorn, I.D.E.; Feindt, P.H.; Kramer, K.; Leemans, R.; Meuwissen, M.P.M.; Spoolder, H.; Sukkel, W. Why we need resilience thinking to meet societal challenges in bio-based production systems. Curr. Opin. Environ. Sustain. 2016, 23, 17-27. [CrossRef]

136. Davoudi, S. Resilience: A bridging concept or a dead end? Plan. Theory Pract. 2012, 13, 299-307. [CrossRef]

137. McNaughton, S.J.; Wolf, L.L. Dominance and the niche in ecological systems. Science 1970, 167, 131-139. [CrossRef]

138. Walker, B.; Carpenter, S.; Anderies, J.; Abel, N.; Cumming, G.; Janssen, M.; Lebel, L.; Norberg, J.; Peterson, G.D.; Pritchard, R. Resilience Management in Social-ecological Systems: A Working Hypothesis for a Participatory Approach. Conserv. Ecol. 2002, 6, 14. Available online: http:/ / www.consecol.org/vol6/iss1/art14 (accessed on 23 June 2021). [CrossRef]

139. Tortajada, C. Water governance: Some critical issues. Water Resour. Dev. 2010, 26, 297-307. [CrossRef]

140. Voinov, A.; Seppelt, R.; Reis, S.; Nabel, J.E.M.S.; Shokravi, S. Values in socio-environmental modelling: Persuasion for action or excuse for inaction. Environ. Model. Softw. 2014, 53, 207-212. [CrossRef]

141. Bowtie Method. Available online: https://cio-wiki.org/wiki/The_Bowtie_Method (accessed on 11 May 2021).

142. Apitz, S.E. Ecosystem services and environmental decision making: Seeking order in complexity. Integr. Environ. Assess. Manag. 2012, 9, 214-230. [CrossRef] [PubMed] 